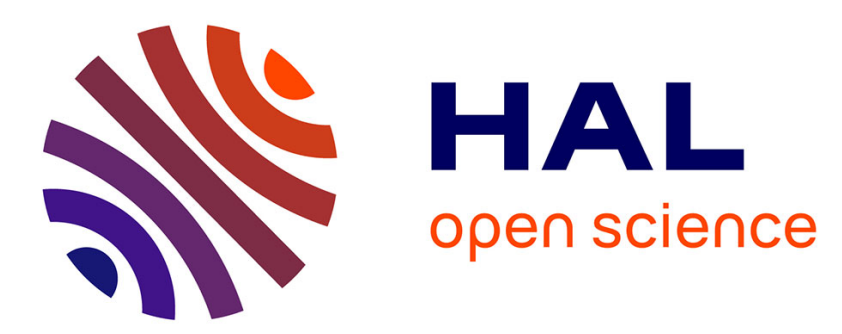

\title{
Limiting genotype frequencies of Y-linked genes through bisexual branching processes with blind choice
}

\author{
G. Alsmeyer, C. Gutiérrez, R. Martínez
}

\section{To cite this version:}

G. Alsmeyer, C. Gutiérrez, R. Martínez. Limiting genotype frequencies of Y-linked genes through bisexual branching processes with blind choice. Journal of Theoretical Biology, 2011, 275 (1), pp.42. 10.1016/j.jtbi.2011.01.024 . hal-00676099

\section{HAL Id: hal-00676099 \\ https://hal.science/hal-00676099}

Submitted on 3 Mar 2012

HAL is a multi-disciplinary open access archive for the deposit and dissemination of scientific research documents, whether they are published or not. The documents may come from teaching and research institutions in France or abroad, or from public or private research centers.
L'archive ouverte pluridisciplinaire HAL, est destinée au dépôt et à la diffusion de documents scientifiques de niveau recherche, publiés ou non, émanant des établissements d'enseignement et de recherche français ou étrangers, des laboratoires publics ou privés. 


\section{Author's Accepted Manuscript}

Limiting genotype frequencies of Y-linked genes through bisexual branching processes with blind choice

G. Alsmeyer, C. Gutiérrez, R. Martínez

PII: S0022-5193(11)00036-1

DOI: doi:10.1016/j.jtbi.2011.01.024

Reference: YJTBI 6336

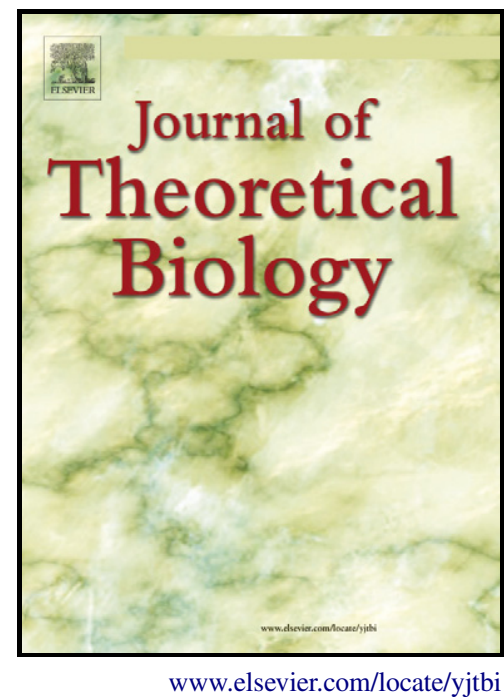

To appear in: Journal of Theoretical Biology

Received date: $\quad 11$ November 2010

Revised date: $\quad 17$ January 2011

Accepted date: 18 January 2011

Cite this article as: G. Alsmeyer, C. Gutiérrez and R. Martínez, Limiting genotype frequencies of Y-linked genes through bisexual branching processes with blind choice, Journal of Theoretical Biology, doi:10.1016/j.jtbi.2011.01.024

This is a PDF file of an unedited manuscript that has been accepted for publication. As a service to our customers we are providing this early version of the manuscript. The manuscript will undergo copyediting, typesetting, and review of the resulting galley proof before it is published in its final citable form. Please note that during the production process errors may be discovered which could affect the content, and all legal disclaimers that apply to the journal pertain. 


\title{
Limiting genotype frequencies of Y-linked genes through bisexual branching processes with blind choice
}

\author{
G. Alsmeyer ${ }^{a}$, C. Gutiérrez ${ }^{b, *}$ and R. Martínez ${ }^{b}$ \\ ${ }^{a}$ Inst. Math. Statistics, Dept. Mathematics and Comp. Science, University of Münster, D-48149 Münster, \\ Germany \\ ${ }^{b}$ Department of Mathematics, University of Extremadura, 06006 Badajoz, Spain
}

\begin{abstract}
The limiting genotype growth rates and the limiting genotype frequencies of Y-linked genes are studied in a two-sex monogamous population. To this end, the evolution of the numbers of females, males, and mating units of each genotype is modeled by a multitype bisexual branching process in which it assumed that the gene has no influence on the mating process. It is deduced from this model that the average numbers of female and male descendants per mating unit of a genotype determine its growth rate, which does not depend on the behaviour of the other genotypes. Hence, the dominant genotype is found. Conditions for the simultaneous survival of genotypes to have positive probability are also investigated. Finally, the main results are illustrated by means of examples.
\end{abstract}

Keywords: Sex-linked inheritance. Bidimensional two-sex stochastic model. Perfect fidelity mating. Rates of growth.

\section{Introduction}

In human and many animal populations the sex of an individual is determined by a pair of chromosomes $X$ and $Y$. The females are homozygous and carry $X X$ chromosomes, whereas the males are heterozygous and carry $X Y$ chromosomes. The inheritance of traits may or may not be sex related. For traits on autosomal chromosomes, both sexes have the same probability of expressing the trait. There is also the possibility of sex linkage - phenotypic expression of an allele related to the chromosomal sex of the individual. The present work focuses on Y-linkage. For humans, there are many more $\mathrm{X}$-linked than Y-linked traits because there are far more genes on the $\mathrm{X}$ - than on the $\mathrm{Y}$-chromosome. Nevertheless, recent research has shown the significance of $Y$-linked genes in the biology of humans and other animals, see, for instance, Quintana-Murci and Fellous (2001) or www.nature.com/nature/focus/ychromosome/.

Bisexual branching processes provide a natural class of candidates when looking for an appropriate mathematical model for the propagation of Y-linked genes in two-sex populations. Roughly speaking, these processes form an extension of classical two-type Galton-Watson branching processes by additionally imposing a mating structure. González et al. (2009) have recently introduced a model of this kind for the evolution of $\mathrm{Y}$-linked genes which occur in two allelic forms, called $\mathrm{R}$ and $\mathrm{r}$. They assume monogamous mating (mating with perfect fidelity) with blind choice, which means that females choose their mate without recognizing or caring about his genotype. The latter condition may be justified by the fact that Y-linked genes are typically not expressed in males, or, if they are, do not have any preferential impact on the mating process. Using this model, we shall focus on the evolution of the numbers of R-couples between a female and a type $\mathrm{R}$ male and of $r$-couples between a female and a type $r$ male over successive generations. Our goal is to describe the growth behaviour of this bivariate process and related genotype frequencies under regimes in which at least one of the allele types survives. Of particular interest are situations where this holds true for both types simultaneously (coexistence) with positive probability. Conditions to guarantee this have been identified in the aforementioned work which may also be consulted for further background information and motivation.

\footnotetext{
${ }^{*}$ Corresponding author. Tel.: +34927257195x57571.

E-mail addresses: gerolda@math.uni-muenster.de (G. Alsmeyer), cgutierrez@unex.es (C. Gutiérrez), rmartinez@unex.es (R. Martínez).
} 
This article contains six further sections. Section 2 is devoted to a description of the model including a definition of the Y-linked bisexual Galton-Watson branching process with blind choice (the basic mathematical object we shall be studying). The limiting growth rate of each genotype given the ultimate extinction of the other is derived in Section 3 together with the limiting sex ratio. Section 4 provides sufficient conditions under which indefinite growth of both genotypes has either positive or zero probability. The limiting growth rate of each genotype in the event that both types survive is studied in Section 6 , once again together with the limiting sex ratio. All proofs of the results presented are provided in the final Section 7 .

\section{Description of the model}

The following model, introduced by González et al. (2009), describes the evolution of the number of carriers of a Y-linked gene in a two-sex monogamous population. The gene occurs in two allelic forms, denoted $\mathrm{R}$ and $\mathrm{r}$. Since the $\mathrm{Y}$-chromosome is haploid and specific to males, the population is formed by females and by two types of male, denoted R- and r-males, depending on which allele they carry. There are thus two types of couple, denoted R- and $r$-couples, depending on whether the male is of type $\mathrm{R}$ or type $\mathrm{r}$. By the rules of genetic inheritance, an $\mathrm{x}$-couple can only give birth to females or $\mathrm{x}$-males $(x \in\{r, R\})$.

Assuming non-overlapping generations, labeled by integers $n=0,1,2, \ldots$, and given the number of couples of each type in generation $n$, the stochastic mechanism that determines the number of females, males, and couples of each genotype in the $(n+1)$-th generation may be divided into two stages, reproduction and mating.

In the reproduction phase, the $\mathrm{R}$ - and $\mathrm{r}$-couples of the $n$-th generation, their numbers being denoted by $Z_{n}$ and $Z_{n}$, respectively, produce offspring independently of each other and according to a certain reproduction law which is the same for a given genotype and independent of the generation they belong to. We allow for different reproduction laws for each genotype and also assume that these reproduction laws have finite means and variances. Let $m_{R}$ and $m_{r}$ denote the average number of offspring produced by an R- and r-couple, respectively. An individual offspring is female with probability $\alpha$ and male with probability $1-\alpha$, independently of the sex designation of any other offspring. In particular, $\alpha$ is the same for both genotypes. As a consequence, the average numbers of females and males generated by an R-couple are $\alpha \mathrm{m}_{\mathrm{R}}$ and $(1-\alpha) \mathrm{m}_{\mathrm{R}}$, respectively, while the respective values for an $r$-couple are $\alpha \mathrm{m}_{\mathrm{r}}$ and $(1-\alpha) \mathrm{m}_{\mathrm{r}}$. At the end of the reproduction phase, one has the total numbers $\mathrm{F}_{n+1}, \mathrm{MR}_{n+1}$, and $\mathrm{Mr}_{n+1}$ of females, R-males stemming from R-couples, and of r-males stemming from r-couples, respectively, which together constitute the $(n+1)$-th generation.

In the mating phase, the number of couples of each genotype in the $(n+1)$-th generation is determined, given the total numbers of females, R-males, and r-males in this generation $\left(\mathrm{F}_{n+1}, \mathrm{MR}_{n+1}\right.$, and $\left.\mathrm{Mr}_{n+1}\right)$. We assume monogamous (perfect fidelity) mating, i.e., each individual mates with only one individual of the opposite sex if available. We further assume that the genotype has no impact on the mating mechanism. This is clearly so if the total number of females is greater than or equal to the total number of males because then every male finds a mate in the female population resulting in $Z_{n+1}=\mathrm{MR}_{n+1}$ couples of type $\mathrm{R}$ and $\mathrm{Zr}_{n+1}=\mathrm{Mr}_{n+1}$ couples of type $\mathrm{r}$. However, if the total number of males exceeds the total number of females, then each female picks a male at random without regard for its genotype (blind choice) from the given pool of $\mathrm{MR}_{n+1}+\mathrm{Mr}_{n+1}$ males. As a consequence, the total number of R-couples in the $(n+1)$-th generation has a hypergeometric distribution with parameters $\mathrm{F}_{n+1}, \mathrm{MR}_{n+1}+\mathrm{Mr}_{n+1}$, and $\mathrm{MR}_{n+1}$, while the total number of $\mathrm{r}$-couples in this generation equals the number of remaining females, i.e., $\mathrm{Zr}_{n+1}=\mathrm{F}_{n+1}-\mathrm{ZR}_{n+1}$. Notice that, by symmetry of the model, the law of $\mathrm{Zr}_{n+1}$ is also hypergeometric, the parameters being $\mathrm{F}_{n+1}, \mathrm{MR}_{n+1}+\mathrm{Mr}_{n+1}$, and $\mathrm{Mr}_{n+1}$.

The bivariate sequence $\left(\mathrm{ZR}_{n}, \mathrm{Zr}_{n}\right)_{n \geq 0}$ describing the evolution of the number of mating units of each genotype over generations is called a $\mathrm{Y}$-linked bisexual branching process with blind choice. It is shown 
in González et al. (2009) that each genotype shows the dual behaviour typical for branching processes and known as the extinction-explosion dichotomy. This means that the number of couples of any type is bound to undergo either extinction or indefinite growth. The survival of the population over generations is therefore determined by the three events $A_{\infty, 0}=\left\{\mathrm{ZR}_{n} \rightarrow \infty, \mathrm{Zr}_{n} \rightarrow 0\right\}$, termed R-fixation, $A_{0, \infty}=$ $\left\{\mathrm{ZR}_{n} \rightarrow 0, \mathrm{Zr}_{n} \rightarrow \infty\right\}$, termed r-fixation, and $A_{\infty, \infty}=\left\{\mathrm{ZR}_{n} \rightarrow \infty, \mathrm{Zr}_{n} \rightarrow \infty\right\}$, termed simultaneous survival of both genotypes or coexistence. The following sections are devoted to the study of the asymptotic growth of surviving genotypes in each of these three events.

\section{Survival of only one genotype: Limiting growth rate}

A necessary and sufficient condition for a genotype to have positive probability of fixation is that both the female and the male mean offspring per couple of that genotype are greater than unity (see Result 2 in González et al. (2009)). This is due to the fact that, if fixation of a particular allele has occurred, the corresponding genotype evolves essentially as a bisexual branching process with perfect fidelity mating and the reproduction law of the surviving genotype. The asymptotic properties of this latter process were studied by Bagley (1986), and the following result may be directly deduced from his work.

Result 3.1 Let $\tau_{\mathrm{R}}=\min \left\{\alpha \mathrm{m}_{\mathrm{R}},(1-\alpha) \mathrm{m}_{\mathrm{R}}\right\}$ and $\tau_{\mathrm{r}}=\min \left\{\alpha \mathrm{m}_{\mathrm{r}},(1-\alpha) \mathrm{m}_{\mathrm{r}}\right\}$.

(i) If $\tau_{\mathrm{R}}>1$, then $P\left(A_{\infty, 0}\right)>0$ and there exists a random variable $\mathrm{W}_{\mathrm{R}}$, which is positive and finite on $A_{\infty, 0}$, such that almost surely (a.s.) on $A_{\infty, 0}$

$$
\lim _{n \rightarrow \infty} \frac{\mathrm{ZR}_{n}}{\tau_{\mathrm{R}}^{n}}=\mathrm{W}_{\mathrm{R}}, \quad \lim _{n \rightarrow \infty} \frac{\mathrm{MR}_{n}}{\tau_{\mathrm{R}}^{n}}=\frac{(1-\alpha) \mathrm{m}_{\mathrm{R}}}{\tau_{\mathrm{R}}} \mathrm{W}_{\mathrm{R}} \text { and } \lim _{n \rightarrow \infty} \frac{\mathrm{F}_{n}}{\tau_{\mathrm{R}}^{n}}=\frac{\alpha \mathrm{m}_{\mathrm{R}}}{\tau_{\mathrm{R}}} \mathrm{W}_{\mathrm{R}} .
$$

(ii) If $\tau_{\mathrm{r}}>1$, then $P\left(A_{0, \infty}\right)>0$ and there exists a random variable $\mathrm{W}_{\mathrm{r}}$, which is positive and finite on $A_{0, \infty}$, such that a.s. on $A_{0, \infty}$

$$
\lim _{n \rightarrow \infty} \frac{\mathrm{Zr}_{n}}{\tau_{\mathrm{r}}^{n}}=\mathrm{W}_{\mathrm{r}}, \quad \lim _{n \rightarrow \infty} \frac{\mathrm{Mr}_{n}}{\tau_{\mathrm{r}}^{n}}=\frac{(1-\alpha) \mathrm{m}_{\mathrm{r}}}{\tau_{\mathrm{r}}} \mathrm{W}_{\mathrm{r}} \quad \text { and } \quad \lim _{n \rightarrow \infty} \frac{\mathrm{F}_{n}}{\tau_{\mathrm{r}}^{n}}=\frac{\alpha \mathrm{m}_{\mathrm{r}}}{\tau_{\mathrm{r}}} \mathrm{W}_{\mathrm{r}}
$$

(iii) If $\max \left\{\tau_{\mathrm{R}}, \tau_{\mathrm{r}}\right\}>1$, then $P\left(A_{\infty, 0} \cup A_{0, \infty}\right)>0$ and

$$
\lim _{n \rightarrow \infty} \frac{\mathrm{F}_{n}}{\mathrm{~F}_{n}+\mathrm{M}_{n}}=\alpha \text { a.s. on } A_{\infty, 0} \cup A_{0, \infty} \text {, }
$$

where $\mathrm{M}_{n}=\mathrm{MR}_{n}+\mathrm{Mr}_{n}$ denotes the total number of males in generation $n$.

Intuitively speaking, assertion (i) states that, if the r-couples have disappeared while the R-couples have not, the numbers of R-couples, R-males, and females grow geometrically at rate $\tau_{\mathrm{R}}$. This rate depends on the probability $\alpha$ of an offspring being a female and on the mean total number of offspring per R-couple, viz. $\mathrm{m}_{\mathrm{R}}$. Indeed, it equals the mean number of females per R-couple if $\alpha \leq 0.5$, and the mean number of males per R-couple otherwise. A similar intuitive meaning can be given for assertion (ii). Finally, assertion (iii) states that the limiting sex ratio of the population in the events of fixation only depends on the probability of an offspring being female.

\section{Conditions for survival of both genotypes (coexistence)}

It should be no surprise that the event of the simultaneous survival of both alleles has positive probability if the mean numbers of females and of males per couple of both genotypes are all greater than unity (i.e., $\left.\min \left\{\alpha \mathrm{m}_{\mathrm{R}}, \alpha \mathrm{m}_{\mathrm{r}},(1-\alpha) \mathrm{m}_{\mathrm{R}},(1-\alpha) \mathrm{m}_{\mathrm{r}}\right\}>1\right)$. This statement was proved in González et al. (2009) (see Result 6 therein) if the probability $\alpha$ for an offspring to be female is different from 0.5 . The case $\alpha=0.5$ is included in the following result.

Result 4.1 Let $\mathrm{ZR}_{0}$ and $\mathrm{Zr}_{0}$ both be positive. 
(i) If $\alpha>0.5$ and $\min \left\{(1-\alpha) \mathrm{m}_{\mathrm{R}},(1-\alpha) \mathrm{m}_{\mathrm{r}}\right\}>1$, then $P\left(A_{\infty, \infty}\right)>0$.

(ii) If $\alpha \leq 0.5$ and $\min \left\{\alpha \mathrm{m}_{\mathrm{R}}, \alpha \mathrm{m}_{\mathrm{r}}\right\}>1$, then $P\left(A_{\infty, \infty}\right)>0$.

However, if the mean number of male offspring per couple of either genotype is less than or equal to unity (i.e., $\left.\min \left\{(1-\alpha) \mathrm{m}_{\mathrm{R}},(1-\alpha) \mathrm{m}_{\mathrm{r}}\right\} \leq 1\right)$, or if the mean number of female offspring per couple of either genotype is strictly less than unity (i.e., $\min \left\{\alpha \mathrm{m}_{\mathrm{R}}, \alpha \mathrm{m}_{\mathrm{r}}\right\}<1$ ), then simultaneous survival of both genotypes has probability zero (see Result 4 in González et al. (2009)). This leaves one open case, namely when the mean number of female descendants equals unity for couples of one genotype, while being greater than unity for couples of the other genotype. The following result takes care of this case for which one should notice that the probability for a descendant to be female is necessarily less than 0.5 .

Result 4.2 Suppose that $\alpha<0.5$ and either $\alpha \mathrm{m}_{\mathrm{R}}=1<\alpha \mathrm{m}_{\mathrm{r}}$ or $\alpha \mathrm{m}_{\mathrm{r}}=1<\alpha \mathrm{m}_{\mathrm{R}}$ holds true. Put $\tau=\max \left\{\alpha \mathrm{m}_{\mathrm{R}}, \alpha \mathrm{m}_{\mathrm{r}}\right\}$. Then either $P\left(A_{\infty, \infty}\right)=0$ or

$$
\lim _{n \rightarrow \infty} \frac{Z_{n}}{\tau^{n}}=0 \quad \text { and } \quad \liminf _{n \rightarrow \infty} \frac{Z_{n}}{\rho^{n}}=0 \quad \text { a.s. on } A_{\infty, \infty}
$$

for any $\rho \in(1, \tau)$, where $\mathbf{Z}_{n}=\mathrm{ZR}_{n}+\mathrm{Zr}_{n}$.

For an intuitive interpretation, let us consider the situation when $\alpha<0.5$ and $\alpha \mathrm{m}_{\mathrm{R}}=1<\alpha \mathrm{m}_{\mathrm{r}}$. Then $\tau$ equals $\alpha \mathrm{m}_{\mathrm{r}}$, which means that the r-genotype dominates the R-genotype, and $\tau$ constitutes the exact geometric growth rate of the number of $r$-couples in the event of fixation of the r-genotype (see Result 3.1). However, we infer from the above result that simultaneous survival of both genotypes entails that the number of couples, and in particular of $r$-couples, grows at a rate less than $\tau$. Indeed, the growth rate drops infinitely often below any $\rho \in(1, \tau)$. Hence, the competition of $\mathbf{r}$ - and $\mathbf{R}$-males for females has a considerable effect as opposed to the situation of fixation where one type eventually disappears. Even so, the result raises the question as to whether $P\left(A_{\infty, \infty}\right)>0$ does occur at all under the stated conditions. We believe that an answer not only would require much deeper and more sophisticated mathematical tools, but would lead us beyond the scope and purpose of the present communication.

Let is now proceed with an illustration of the above result. Assume that $\alpha<0.5$ and $\alpha \mathrm{m}_{\mathrm{R}}=1<\alpha \mathrm{m}_{\mathrm{r}}$. Based on the behaviour of R-couples, González et al. (2009) conjectured that simultaneous survival of both genotypes has probability zero. Further evidence for this conjecture is provided by the following argument regarding the behaviour of $r$-couples. As in the aforementioned article, we consider the situation where $\alpha=0.4$ and reproduction laws are Poisson with means $\mathrm{m}_{\mathrm{R}}=2.5$ and $\mathrm{m}_{\mathrm{r}}=2.52$, which implies $\alpha \mathrm{m}_{\mathrm{R}}=1$ and $\alpha \mathrm{m}_{\mathrm{r}}=1.008>1$, and hence $\tau=\alpha \mathrm{m}_{\mathrm{r}}$. By Monte-Carlo simulation, we generated realizations of $\left(\mathrm{ZR}_{n}, \mathrm{Zr}_{n}\right)_{n \geq 0}$ with $\mathrm{ZR}_{0}=\mathrm{Zr}_{0}=3$ that survived 1000 generations. Typical outcomes are displayed in Figure 1. For these, Figure 2 shows the behaviour of $\left(\mathrm{ZR}_{n}+\mathrm{Zr}_{n}\right) / \tau^{n}$ (left plot) and $\log \left(\mathrm{ZR}_{n}+\mathrm{Zr}_{n}\right)$ (right plot) over generations. These indicate that the total number of couples normalized by the growth rate of the dominant genotype approaches a positive limit. For the sample $\left(n, \log \left(\mathrm{ZR}_{n}+\mathrm{Zr}_{n}\right)\right)_{n=700, \ldots, 1000}$, we also calculated the sample linear correlation coefficient to be 0.999369 and the slope of the regression line to be 0.007913 , which is very close to the theoretical value $\log \tau=0.007968$. In view of Result 4.2 and coherent with the above conjecture, we conclude that in this realization the R-genotype is likely to disappear so that fixation of the r-genotype occurs.

\section{Coexistence: Limiting growth rates and frequencies}

In this section, we return to the situation of Result 4.1 and assume that the mean numbers of females and males per couple of both genotypes are greater than unity, i.e., $\min \left\{\alpha \mathrm{m}_{\mathrm{R}},(1-\alpha) \mathrm{m}_{\mathrm{R}}, \alpha \mathrm{m}_{\mathrm{r}},(1-\alpha) \mathrm{m}_{\mathrm{r}}\right\}>1$ (which conforms to the condition in Result 4.1(i) or (ii) depending on whether $\alpha>0.5$ or $\alpha \leq 0.5$ ). Then simultaneous survival of both genotypes occurs with positive probability, so that it makes sense to determine the limiting growth rates for the numbers of females, R-males, R-couples, and their $r$ counterparts. Answers are provided by the following two results that deal with the two cases $\alpha>0.5$ and $\alpha \leq 0.5$ separately. We note and will prove in Lemma 6 that in the first case the number of females 

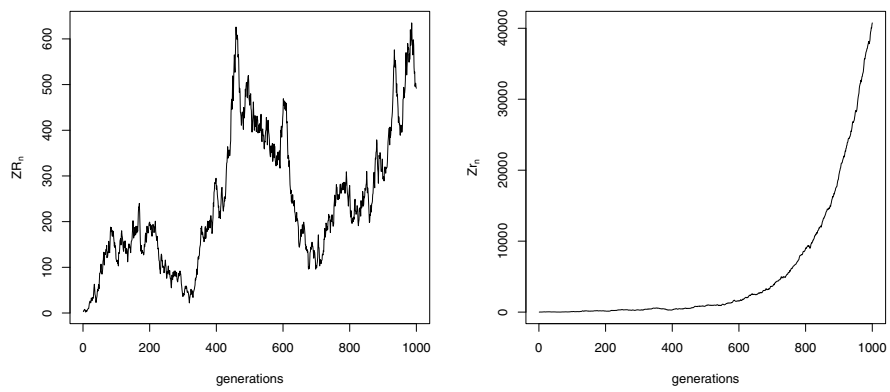

Figure 1: Realizations of $\mathrm{ZR}_{n}$ (left plot) and $\mathrm{Zr}_{n}$ (right plot) in a process where both genotypes have survived until generation 1000 .
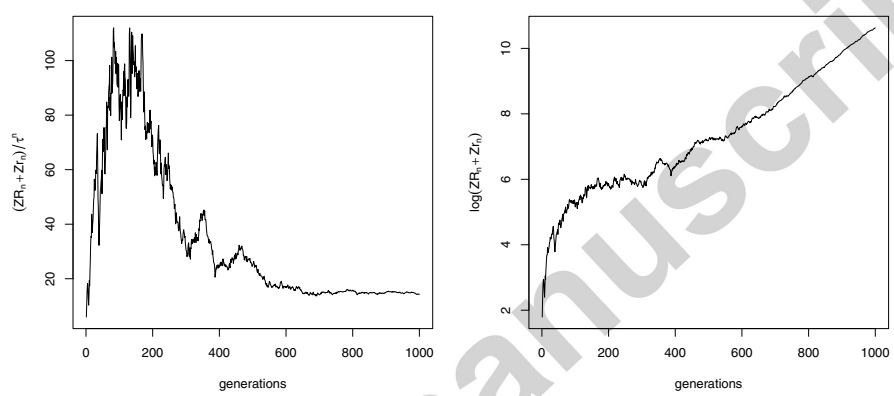

Figure 2: Realizations of $\left(\mathrm{ZR}_{n}+\mathrm{Zr}_{n}\right) / \tau^{n}$ (left plot) and $\log \left(\mathrm{ZR}_{n}+\mathrm{Zr}_{n}\right)$ (right plot) in a process where both genotypes have survived until generation 1000 .

always exceeds the number of males from some generation onwards, whereas the number of males is eventually always greater than the number of females if $\alpha<0.5$. The boundary case $\alpha=0.5$ is more delicate because neither of the previous two statements holds true (oscillating situation). We therefore expect results that depend on the value of $\alpha$.

Result 5.1 If $\alpha>0.5$ and $\min \left\{(1-\alpha) \mathrm{m}_{\mathrm{R}},(1-\alpha) \mathrm{m}_{\mathrm{r}}\right\}>1$, then there exist nonnegative and finite random variables $\mathrm{W}_{\mathrm{R}}$ and $\mathrm{W}_{\mathrm{r}}$, which are positive on $A_{\infty, \infty}$, such that a.s. on this event

$$
\begin{aligned}
& \lim _{n \rightarrow \infty} \frac{\mathrm{ZR}_{n}}{\left((1-\alpha) \mathrm{m}_{\mathrm{R}}\right)^{n}}=\mathrm{W}_{\mathrm{R}} \text { and } \lim _{n \rightarrow \infty} \frac{\mathrm{Zr}_{n}}{\left((1-\alpha) \mathrm{m}_{\mathrm{r}}\right)^{n}}=\mathrm{W}_{\mathrm{r}}, \\
& \lim _{n \rightarrow \infty} \frac{\mathrm{MR}_{n}}{\left((1-\alpha) \mathrm{m}_{\mathrm{R}}\right)^{n}}=\mathrm{W}_{\mathrm{R}} \text { and } \lim _{n \rightarrow \infty} \frac{\mathrm{Mr}_{n}}{\left((1-\alpha) \mathrm{m}_{\mathrm{r}}\right)^{n}}=\mathrm{W}_{\mathrm{r}}
\end{aligned}
$$

and

$$
\lim _{n \rightarrow \infty} \frac{\mathrm{F}_{n}}{\tau^{n}}=\frac{\alpha}{1-\alpha}\left(\mathrm{W}_{\mathrm{R}} I_{\left\{\mathrm{m}_{\mathrm{R}} \geq \mathrm{m}_{\mathrm{r}}\right\}}+\mathrm{W}_{\mathrm{r}} I_{\left\{\mathrm{m}_{\mathrm{R}} \leq \mathrm{m}_{\mathrm{r}}\right\}}\right),
$$

where $\tau=\max \left\{(1-\alpha) \mathrm{m}_{\mathrm{R}},(1-\alpha) \mathrm{m}_{\mathrm{r}}\right\}$ and $I_{\{a \geq b\}}$ is equal to 1 if $a \geq b$, and 0 otherwise.

Intuitively speaking, the total numbers of couples and males of each genotype grow geometrically at the same rate, defined by the mean number of males generated by a couple of this genotype. This follows from the fact that, from some generation onwards, the total number of couples of each genotype is determined by the total number of males of this type. Moreover, the total number of females in the population grows geometrically as well, but at a rate defined by the mean number of males generated by the dominant 

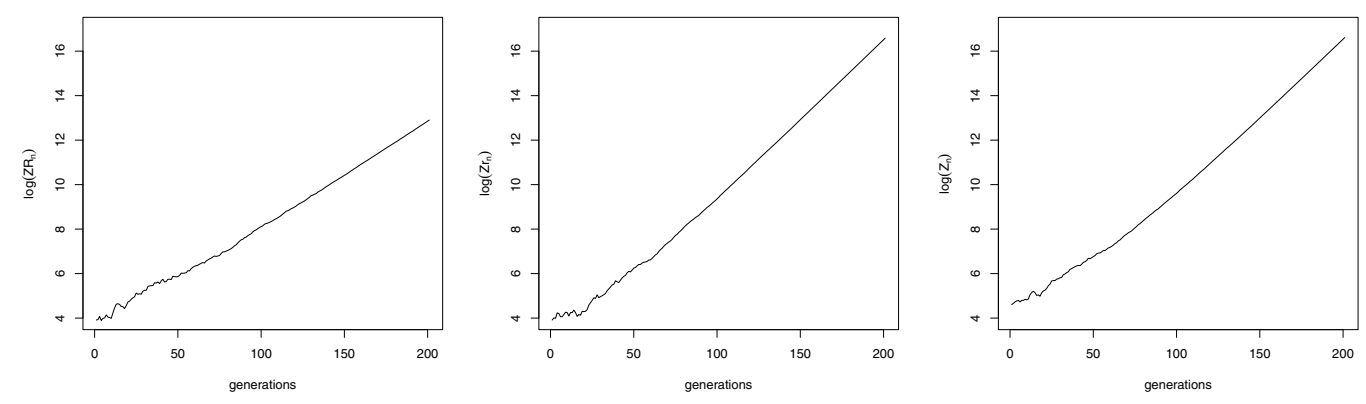

Figure 3: Logarithm of the total number of R-couples (left plot), the total number of r-couples (middle plot), and the total number of couples (right plot) from a path of a process in which both genotypes have survived until generation 200.

genotype. We note that this also is the case for the total number of couples and the total number of males.

The remaining cases $\alpha<0.5$ and $\alpha=0.5$, though qualitatively different as explained above, can be dealt with together in the following result.

Result 5.2 If $\alpha \leq 0.5$ and $\min \left\{\alpha \mathrm{m}_{\mathrm{R}}, \alpha \mathrm{m}_{\mathrm{r}}\right\}>1$, then there exist nonnegative and finite random variables $\mathrm{W}_{\mathrm{R}}^{*}$ and $\mathrm{W}_{\mathrm{r}}^{*}$, which are positive on $A_{\infty, \infty}$, such that a.s. on this event

$$
\begin{gathered}
\lim _{n \rightarrow \infty} \frac{\mathrm{ZR}_{n}}{\left(\alpha \mathrm{m}_{\mathrm{R}}\right)^{n}}=\mathrm{W}_{\mathrm{R}}^{*} \text { and } \lim _{n \rightarrow \infty} \frac{\mathrm{Zr}_{n}}{\left(\alpha \mathrm{m}_{\mathrm{r}}\right)^{n}}=\mathrm{W}_{\mathrm{r}}^{*}, \\
\lim _{n \rightarrow \infty} \frac{\mathrm{MR}_{n}}{\left(\alpha \mathrm{m}_{\mathrm{R}}\right)^{n}}=\frac{1-\alpha}{\alpha} \mathrm{W}_{\mathrm{R}}^{*} \text { and } \lim _{n \rightarrow \infty} \frac{\mathrm{Mr}_{n}}{\left(\alpha \mathrm{m}_{\mathrm{r}}\right)^{n}}=\frac{1-\alpha}{\alpha} \mathrm{W}_{\mathrm{r}}^{*},
\end{gathered}
$$

and

$$
\lim _{n \rightarrow \infty} \frac{\mathrm{F}_{n}}{\tau^{n}}=\left(\mathrm{W}_{\mathrm{R}}^{*} I_{\left\{\mathrm{m}_{\mathrm{R}} \geq \mathrm{m}_{\mathrm{r}}\right\}}+\mathrm{W}_{\mathrm{r}}^{*} I_{\left\{\mathrm{m}_{\mathrm{R}} \leq \mathrm{m}_{\mathrm{r}}\right\}}\right)
$$

where $\tau=\max \left\{\alpha \mathrm{m}_{\mathrm{R}}, \alpha \mathrm{m}_{\mathrm{r}}\right\}$.

Notice that, upon setting $\mathrm{W}_{\mathrm{R}}=\frac{1-\alpha}{\alpha} \mathrm{W}_{\mathrm{R}}^{*}$ and $\mathrm{W}_{\mathrm{r}}=\frac{1-\alpha}{\alpha} \mathrm{W}_{\mathrm{r}}^{*}$, the assertions of Result 5.1 and Result 5.2 actually coincide in the case $\alpha=0.5$, as one would expect.

We shall illustrate the above results by another Monte-Carlo simulation for which we assumed $\alpha=0.5$ and reproduction laws to be Poisson with means $m_{R}=2.10$ and $m_{r}=2.15$. Figure 3 shows semi-logarithmic plots of the total number of R-couples (left plot), the total number of r-couples (middle plot), and the total number of couples (right plot) from a realization of $\left(Z_{n}, Z_{r}\right)_{n \geq 0}$ with $Z_{0}=Z_{0}=50$ in which both genotypes have survived until generation 200. One observes that the dominant r-genotype has the greater growth rate, which is the same for the total number of couples.

It is now immediate to deduce from Results 5.1 and 5.2 the limiting genotype frequencies and the limiting sex ratio.

Result 5.3 If $\min \left\{\alpha \mathrm{m}_{\mathrm{R}},(1-\alpha) \mathrm{m}_{\mathrm{R}}, \alpha \mathrm{m}_{\mathrm{r}},(1-\alpha) \mathrm{m}_{\mathrm{r}}\right\}>1$ and $\mathrm{W}_{\mathrm{R}}, \mathrm{W}_{\mathrm{r}}, \mathrm{W}_{\mathrm{R}}^{*}, \mathrm{~W}_{\mathrm{r}}^{*}$ are as in Results 5.1 and 5.2, then a.s. on $A_{\infty, \infty}$

$$
\lim _{n \rightarrow \infty} \frac{\mathrm{ZR}_{n}}{\mathrm{Z}_{n}}=\mathrm{W}, \quad \lim _{n \rightarrow \infty} \frac{\mathrm{MR}_{n}}{\mathrm{M}_{n}}=\mathrm{W} \quad \text { and } \quad \lim _{n \rightarrow \infty} \frac{\mathrm{F}_{n}}{\mathrm{~F}_{n}+\mathrm{M}_{n}}=\alpha,
$$



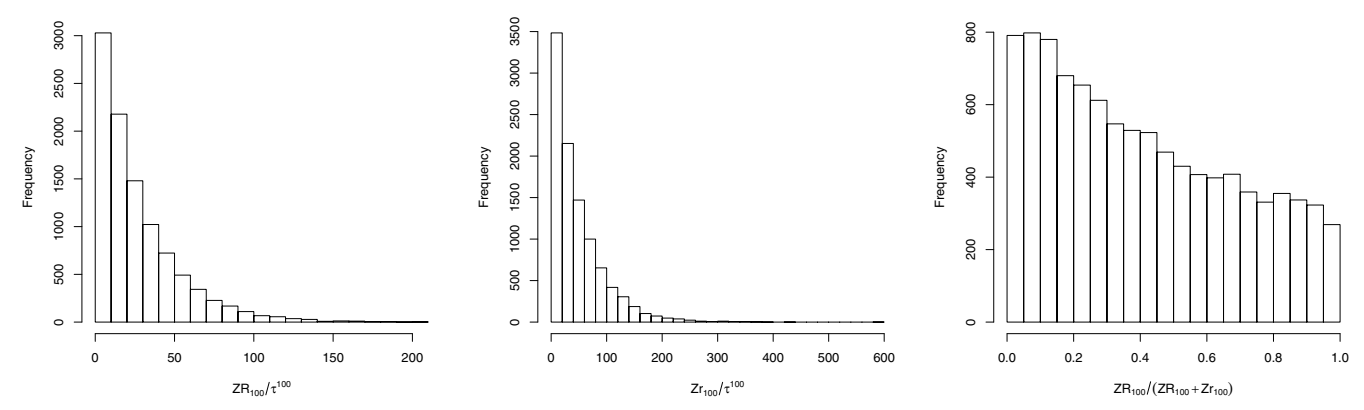

Figure 4: Histogram of $Z_{100} / \tau^{100}$ (left plot), $\mathrm{Zr}_{100} / \tau^{100}$ (middle plot) and $\mathrm{ZR}_{100} /\left(\mathrm{ZR}_{100}+\mathrm{Zr}_{100}\right)($ right plot).

where

$$
\mathrm{W}= \begin{cases}1, & \text { if } \mathrm{m}_{\mathrm{R}}>\mathrm{m}_{\mathrm{r}} \\ \mathrm{W}_{\mathrm{R}} /\left(\mathrm{W}_{\mathrm{R}}+\mathrm{W}_{\mathrm{r}}\right), & \text { if } \mathrm{m}_{\mathrm{R}}=\mathrm{m}_{\mathrm{r}} \text { and } \alpha>0.5 \\ \mathrm{~W}_{\mathrm{R}}^{*} /\left(\mathrm{W}_{\mathrm{R}}^{*}+\mathrm{W}_{\mathrm{r}}^{*}\right), & \text { if } \mathrm{m}_{\mathrm{R}}=\mathrm{m}_{\mathrm{r}} \text { and } \alpha \leq 0.5 \\ 0, & \text { if } \mathrm{m}_{\mathrm{R}}<\mathrm{m}_{\mathrm{r}},\end{cases}
$$

recalling that $\mathrm{Z}_{n}=\mathrm{ZR}_{n}+\mathrm{Zr}_{n}$ and $\mathrm{M}_{n}=\mathrm{MR}_{n}+\mathrm{Mr}_{n}$.

One thus sees that the limiting sex ratio in the population does not depend on the Y-linked gene but only on the probability of an offspring being female. Moreover, neither does the limiting R-genotype frequency among mating units and males depend on $\alpha$, but equals unity if $\mathrm{m}_{\mathrm{R}}$ is greater than $\mathrm{m}_{\mathrm{r}}$, i.e., if the $\mathrm{R}$ genotype is dominant. Equality of $\mathrm{m}_{\mathrm{R}}$ and $\mathrm{m}_{\mathrm{r}}$ implies $0<\mathrm{W}<1$ a.s. on $A_{\infty, \infty}$, since $\mathrm{W}_{\mathrm{R}}, \mathrm{W}_{\mathrm{r}}, \mathrm{W}_{\mathrm{R}}^{*}, \mathrm{~W}_{\mathrm{r}}^{*}$ are all a.s. positive and finite on this event. The limiting genotype frequencies thus being strictly between zero and unity, we conclude that there is no dominant genotype in this case. Naturally, the results for the r-genotype are analogous, replacing $\mathrm{W}$ with $1-\mathrm{W}$.

To illustrate the statistical properties of the random variable $W$ in the case $m_{R}=m_{r}$, we consider the situation where $\alpha=0.4$ and reproduction laws are Poisson and geometric with common mean 2.55 for the R-and r-genotypes. We put $\tau=\alpha \mathrm{m}_{\mathrm{R}}=1.02$. Based on the simulation of 10000 simulations over 100 generations with both genotypes surviving this time span, Figure 4 shows the empirical distributions (displayed as histograms) of the total numbers of R-couples (left plot) and r-couples (middle plot) in generation 100, normalized by $\tau^{100}$, i.e., $\mathrm{ZR}_{100} / \tau^{100}$ and $\mathrm{Zr}_{100} / \tau^{100}$, respectively. The behaviour of the proportion of $\mathrm{R}$-couples in generation 100, i.e., $Z \mathrm{R}_{100} /\left(\mathrm{ZR}_{100}+\mathrm{Zr}_{100}\right)$, is shown in the right plot. The largest observed values appear for $\mathrm{Zr}_{100} / \tau^{100} \approx \mathrm{W}_{\mathrm{r}}^{*}$ which may be attributed to the fact that the Poisson reproduction law for R-couples has a smaller dispersion than the geometric reproduction law of r-couples. As a consequence, the limiting R-genotype frequency is more likely to be less than one-half, i.e. $P(\mathrm{~W}<0.5)>0.5$.

\section{Concluding remarks}

With a focus on $\mathrm{Y}$-linked genes that occur in two allelic forms $\mathrm{R}$ and $\mathrm{r}$, this work has dealt with the classical problem in population genetics of determining genotype frequencies. Adopting a generation point of view, we studied the evolution of the number of carriers of the two alleles in a two-sex monogamous population under the assumption that the gene considered has no effect on the mating process. This means that a female chooses her mate without regard to, or even knowledge of, his genotype (blind choice). An appropriate model leading to so-called Y-linked bisexual branching processes with blind choice was provided by González et al. (2009). Their work should also be consulted for good background information about the biological relevance of studying $\mathrm{Y}$-linkage. By applying advanced mathematical 
tools from the theory of branching processes, see Asmussen and Hering (1983) (Chapter XI), we derived the limiting growth rates of surviving genotypes as functions of the mean numbers of females and males generated by a mating unit (couple).

In particular, a genotype $x \in\{R, r\}$ has positive probability of survival if the mean numbers of female and male descendants per $x$-couple are both greater than unity. Our results then show that the growth rates for the numbers of $x$-couples and $x$-males coincide in the event of survival. In particular, both quantities grow geometrically, and the limiting growth rate equals the mean number of female offspring per $\mathrm{x}$-couple if the probability $\alpha$ for a descendant to be female is less than 0.5 , whereas it equals the mean number of male offspring per $x$-couple if $\alpha \geq 0.5$. Furthermore, this behaviour does not depend on the extinction or survival of the other genotype. However, if both genotypes survive, it is impossible for the limiting growth rate of one type to be determined by the mean number of female offspring per couple of this type while for the other genotype this asymptotic rate equals the number of male offspring per couple of the respective type. More precisely, these rates turn out to be either $\alpha \mathrm{m}_{\mathrm{R}}$ and $\alpha \mathrm{m}_{\mathrm{r}}$, or $(1-\alpha) \mathrm{m}_{\mathrm{R}}$ and $(1-\alpha) \mathrm{m}_{\mathrm{r}}$, respectively. As a consequence, there exists a dominant genotype with limiting frequency unity on the event of joint survival if $m_{R} \neq m_{r}$, while $m_{R}=m_{r}$ entails balanced coexistence of the two types in the sense that their limiting frequencies are a.s. positive and random. Finally, we found that the limiting sex ratio equals the probability of being female, and thus does not depend on the $\mathrm{Y}$-linked gene.

In conclusion, the limiting behaviour of Y-linked genes in a bisexual branching model with blind choice may be different from those obtained in classical genetic models, for example, in models for which the Hardy-Weinberg law holds true and thus no dominant genotype exists in the population. This may be due to the fact that the population size is considered constant in these models which constrains the modes of long-term behaviour. However, even with varying population size a different limiting behaviour is possible and indeed observed, for example, for Y-linked genes modeled by bisexual branching processes with preferential mating (see González et al. (2006) and González et al. (2008)), where the behaviour of one genotype depends on the survival of the other.

\section{Proofs}

\subsection{Setup and basic notation}

We shall first provide a formal definition of the model. Consider two independent sequences

$$
\left\{\left(\mathrm{FR}_{n, l}, \mathrm{MR}_{n, l}\right): n=0,1, \ldots ; l=1,2 \ldots\right\} \quad \text { and } \quad\left\{\left(\mathrm{Fr}_{n, l}, \mathrm{Mr}_{n, l}\right): n=0,1, \ldots ; l=1,2 \ldots\right\}
$$

of independent, identically distributed, nonnegative, and integer-valued bivariate random vectors such that, for $\mathrm{x} \in\{\mathrm{R}, \mathrm{r}\},\left(\mathrm{Fx}_{n, l}, \mathrm{M} \mathrm{x}_{n, l}\right)$ represents the total number of females and males, respectively, stemming from the $l$-th $\mathrm{x}$-couple in the $n$-th generation. We assume that the distribution of $\mathrm{Fx}_{n, l}+\mathrm{Mx}_{n, l}$ has mean $\mathrm{m}_{\mathrm{x}}$ and finite variance. Moreover, the conditional distribution of $\left(\mathrm{Fx}_{n, l}, \mathrm{Mx}_{n, l}\right)$ given $\mathrm{Fx}_{n, l}+\mathrm{Mx}_{n, l}=k$ is multinomial with parameters $k, \alpha$, and $(1-\alpha)$, for $k \geq 0$ and $0<\alpha<1$, where $\alpha$ represents the probability for an offspring to be female. It follows that $E\left[\mathrm{Fx}_{n, l}\right]=\alpha \mathrm{m}_{\mathrm{x}}$ and $E\left[\mathrm{M} \mathrm{x}_{n, l}\right]=(1-\alpha) \mathrm{m}_{\mathrm{x}}$ for each $x \in\{R, r\}$.

Given the total number of R-couples and r-couples in generation $n$, denoted by $\mathrm{ZR}_{n}$ and $\mathrm{Zr}_{n}$, respectively, the total number of female and male offspring generated by each genotype is given by

$$
\left(\mathrm{FR}_{n+1}, \mathrm{MR}_{n+1}\right)=\sum_{l=1}^{\mathrm{ZR}_{n}}\left(\mathrm{FR}_{n, l}, \mathrm{MR}_{n, l}\right) \text { and }\left(\mathrm{Fr}_{n+1}, \mathrm{Mr}_{n+1}\right)=\sum_{l=1}^{\mathrm{Zr}_{n}}\left(\mathrm{Fr}_{n, l}, \mathrm{Mr}_{n, l}\right)
$$

with the usual convention that the empty sum is defined as zero. Here, $F x_{n+1}$ represents the number of females and $\mathrm{Mx}_{n+1}$ the number of males in the $(n+1)$-th generation stemming from $\mathrm{x}$-couples for $x \in\{R, r\}$. Consequently, the total number of female and male offspring comprising this generation is given by

$$
\mathrm{F}_{n+1}=\mathrm{FR}_{n+1}+\mathrm{Fr}_{n+1} \quad \text { and } \quad \mathrm{M}_{n+1}=\mathrm{MR}_{n+1}+\mathrm{Mr}_{n+1} \text {, }
$$


respectively.

Given $\left(\mathrm{F}_{n+1}, \mathrm{MR}_{n+1}, \mathrm{Mr}_{n+1}\right)$, and taking into account that monogamous mating is assumed, one obtains

$$
\mathrm{Z}_{n+1}=\mathrm{F}_{n+1} \wedge \mathrm{M}_{n+1}
$$

as the total number of couples in the $(n+1)$-th generation. Here $a \wedge b:=\min \{a, b\}$ for real numbers $a, b$. Moreover, $\mathrm{Z}_{n+1}=\mathrm{M}_{n+1}$ entails $\mathrm{ZR}_{n+1}=\mathrm{MR}_{n+1}$ and $\mathrm{Zr}_{n+1}=\mathrm{Mr}_{n+1}$, whereas $\mathrm{Z}_{n+1}=\mathrm{F}_{n+1}$ entails that the conditional distribution of $Z_{n+1}$ is hypergeometric with parameters $\left(F_{n+1}, M_{n+1}, M_{n+1}\right)($ see Hush and Scovel (2005) for details about the hypergeometric distribution) and $\mathrm{Zr}_{n+1}=\mathrm{F}_{n+1}-\mathrm{ZR}_{n+1}$. We note that the process $\left(\mathrm{ZR}_{n}, \mathrm{Zr}_{n}\right)_{n \geq 0}$ forms a homogeneous Markov chain and that all states $(i, j)$ with $i, j \geq 1$ are communicating (see property P2 in González et al. (2009)).

Finally, we introduce the filtrations $\mathcal{G}_{n}=\sigma\left(\mathrm{ZR}_{0}, \mathrm{Zr}_{0}, \mathrm{FR}_{k}, \mathrm{MR}_{k}, \mathrm{Fr}_{k}, \mathrm{Mr}_{k}, \mathrm{ZR}_{k}, \mathrm{Zr}_{k}, k=1, \ldots, n\right), n \geq 1$ $\left(\mathcal{G}_{0}=\sigma\left(\mathrm{ZR}_{0}, \mathrm{Zr}_{0}\right)\right)$ and $\mathcal{F}_{n}=\sigma\left(\mathcal{G}_{n-1}, \mathrm{FR}_{n}, \mathrm{MR}_{n}, \mathrm{Fr}_{n}, \mathrm{Mr}_{n}\right), n \geq 1$. For any $i, j \geq 0$, we write $P_{(i, j)}(\cdot)$ for $P\left(\cdot \mid \mathrm{ZR}_{0}=i, \mathrm{Zr}_{0}=j\right)$ and $E_{(i, j)}[\cdot]$ for $E\left[\cdot \mid \mathrm{ZR}_{0}=i, \mathrm{Zr}_{0}=j\right]$.

\subsection{Proof of Result 4.1}

We have only to consider the case $\alpha=0.5$ and $\min \left\{\alpha \mathrm{m}_{\mathrm{R}}, \alpha \mathrm{m}_{\mathrm{r}}\right\}>1$, referring to the work by González et al. (2009) for all other cases.

One can fix $\varepsilon>0$ so small that $\eta_{1}=\alpha\left(\mathrm{m}_{\mathrm{R}}-\varepsilon\right)\left(1-3 \varepsilon / \min \left\{\mathrm{m}_{\mathrm{R}}+\varepsilon, \mathrm{m}_{\mathrm{r}}+\varepsilon\right\}\right)>1$ and $\eta_{2}=\alpha\left(\mathrm{m}_{\mathrm{r}}-\varepsilon\right)(1-$ $\left.3 \varepsilon / \min \left\{\mathrm{m}_{\mathrm{R}}+\varepsilon, \mathrm{m}_{\mathrm{r}}+\varepsilon\right\}\right)>1$. Let $A_{n}=\left\{\mathrm{ZR}_{n+1}>\eta_{1} \mathrm{ZR}_{n}, \mathrm{Zr}_{n+1}>\eta_{2} \mathrm{Zr}_{n}\right\}$, for all $n \geq 0$. One then has that

$$
\begin{aligned}
P_{(i, j)}\left(A_{\infty, \infty}\right) & \geq P_{(i, j)}\left(\bigcap_{n=0}^{\infty}\left\{\mathrm{ZR}_{n+1}>\eta_{1} \mathrm{ZR}_{n}, \mathrm{Zr}_{n+1}>\eta_{2} \mathrm{Zr}_{n}\right\}\right) \\
& =\lim _{n \rightarrow \infty} P_{(i, j)}\left(\bigcap_{l=0}^{n} A_{l}\right) \\
& =\lim _{n \rightarrow \infty} P_{(i, j)}\left(A_{0}\right) \prod_{l=1}^{n} P_{(i, j)}\left(A_{l} \mid \bigcap_{k=0}^{l-1} A_{k}\right) .
\end{aligned}
$$

Since $\left(\mathrm{ZR}_{n}, \mathrm{Zr}_{n}\right)_{n \geq 0}$ satisfies the Markov property, one further infers for any $n \geq 1$

$$
\begin{aligned}
P_{(i, j)}\left(A_{n} \mid \bigcap_{k=0}^{n-1} A_{k}\right) & =P_{(i, j)}\left(A_{n} \mid \bigcup_{i^{\prime}, j^{\prime}>0}\left\{\left(\mathrm{ZR}_{n}, \mathrm{Zr}_{n}\right)=\left(i^{\prime}, j^{\prime}\right)\right\} \cap \bigcap_{k=0}^{n-1} A_{k}\right) \\
& \geq \inf _{i^{\prime}>\eta_{1}^{n} i, j^{\prime}>\eta_{2}^{n} j} P_{(i, j)}\left(A_{n} \mid\left\{\left(\mathrm{ZR}_{n}, \mathrm{Zr}_{n}\right)=\left(i^{\prime}, j^{\prime}\right)\right\} \cap \bigcap_{k=0}^{n-1} A_{k}\right) \\
& =\inf _{i^{\prime}>\eta_{1}^{n} i, j^{\prime}>\eta_{2}^{n} j} P_{\left(i^{\prime}, j^{\prime}\right)}\left(A_{0}\right) .
\end{aligned}
$$

Therefore, a suitable lower positive bound for the last infimum (as a function of $n$ ) needs to be found in order to conclude that $P_{(i, j)}\left(A_{\infty, \infty}\right)>0$. Towards this end, one first notes that

$$
\begin{aligned}
A_{0}^{c}= & \left\{\mathrm{ZR}_{1} \leq \eta_{1} \mathrm{ZR}_{0}\right\} \cup\left\{\mathrm{Zr}_{1} \leq \eta_{2} \mathrm{Zr}_{0}\right\} \\
\subseteq \quad & \left\{\mathrm{ZR}_{1} \leq \eta_{1} \mathrm{ZR}_{0}, \mathrm{MR}_{1}>\eta_{1} \mathrm{ZR}_{0}, \mathrm{~F}_{1}>\mathrm{M}_{1}\right\} \cup\left\{\mathrm{MR}_{1} \leq \eta_{1} \mathrm{ZR}_{0}\right\} \\
& \cup\left(D \cap\left\{\mathrm{ZR}_{1} \leq \eta_{1} \mathrm{ZR}_{0}, \mathrm{~F}_{1} \leq \mathrm{M}_{1}\right\}\right) \cup D^{c} \\
& \cup\left\{\mathrm{Zr}_{1} \leq \eta_{2} \mathrm{Zr}_{0}, \mathrm{Mr}_{1}>\eta_{2} \mathrm{Zr}_{0}, \mathrm{~F}_{1}>\mathrm{M}_{1}\right\} \cup\left\{\mathrm{Mr}_{1} \leq \eta_{2} \mathrm{Zr}_{0}\right\} \\
& \cup\left(D \cap\left\{\mathrm{Zr}_{1} \leq \eta_{2} \mathrm{Zr}_{0}, \mathrm{~F}_{1} \leq \mathrm{M}_{1}\right\}\right)
\end{aligned}
$$


where $D=A_{\mathrm{FR}} \cap A_{\mathrm{MR}} \cap A_{\mathrm{Fr}} \cap A_{\mathrm{Mr}}$, with

$$
\begin{aligned}
A_{\mathrm{FR}} & =\left\{\left|\mathrm{FR}_{1}-\alpha \mathrm{m}_{\mathrm{R}} \mathrm{ZR}_{0}\right| \leq \alpha \varepsilon \mathrm{ZR}_{0}\right\}, \quad A_{\mathrm{MR}}=\left\{\left|\mathrm{MR}_{1}-(1-\alpha) \mathrm{m}_{\mathrm{R}} \mathrm{ZR}_{0}\right| \leq(1-\alpha) \varepsilon \mathrm{ZR}_{0}\right\} \\
A_{\mathrm{Fr}} & =\left\{\left|\mathrm{Fr}_{1}-\alpha \mathrm{m}_{\mathrm{r}} \mathrm{Zr}_{0}\right| \leq \alpha \varepsilon \mathrm{Zr}_{0}\right\} \quad \text { and } \quad A_{\mathrm{Mr}}=\left\{\left|\mathrm{Mr}_{1}-(1-\alpha) \mathrm{m}_{\mathrm{r}} \mathrm{Zr}_{0}\right| \leq(1-\alpha) \varepsilon \mathrm{Zr}_{0}\right\} .
\end{aligned}
$$

Since $\left(Z_{1}, Z_{1}\right)=\left(M R_{1}, M_{1}\right)$ if $F_{1}>M_{1}$, one infers that

$$
\begin{array}{ll} 
& P_{\left(i^{\prime}, j^{\prime}\right)}\left(\mathrm{ZR}_{1} \leq \eta_{1} \mathrm{ZR}_{0}, \mathrm{MR}_{1}>\eta_{1} \mathrm{ZR}_{0}, \mathrm{~F}_{1}>\mathrm{M}_{1}\right)=0 \\
\text { and } & P_{\left(i^{\prime}, j^{\prime}\right)}\left(\mathrm{Zr}_{1} \leq \eta_{2} \mathrm{Zr}_{0}, \mathrm{Mr}_{1}>\eta_{2} \mathrm{Zr}_{0}, \mathrm{~F}_{1}>\mathrm{M}_{1}\right)=0
\end{array}
$$

for all $i^{\prime}, j^{\prime} \geq 1$. Moreover, as $\eta_{1}<\alpha\left(\mathrm{m}_{\mathrm{R}}-\varepsilon\right), \eta_{2}<\alpha\left(\mathrm{m}_{\mathrm{r}}-\varepsilon\right), \alpha=1-\alpha=0.5$, and reproduction laws are assumed to have finite variances, it follows with the help of Chebyshev's inequality that

$$
\begin{aligned}
P_{\left(i^{\prime}, j^{\prime}\right)}\left(\mathrm{MR}_{1} \leq \eta_{1} \mathrm{ZR}_{0}\right) & \leq P_{\left(i^{\prime}, j^{\prime}\right)}\left(\mathrm{MR}_{1} \leq \alpha\left(\mathrm{m}_{\mathrm{R}}-\varepsilon\right) \mathrm{ZR}_{0}\right) \\
& =P_{\left(i^{\prime}, j^{\prime}\right)}\left(\sum_{k=1}^{i^{\prime}}\left(\mathrm{MR}_{k 0}-(1-\alpha) \mathrm{m}_{\mathrm{R}}\right) \leq-\varepsilon i^{\prime}\right) \leq \frac{C_{1}}{i^{\prime}}
\end{aligned}
$$

for some positive constant $C_{1}$. Similar arguments give

$$
P_{\left(i^{\prime}, j^{\prime}\right)}\left(\mathrm{Mr}_{1} \leq \eta_{2} \mathrm{Zr}_{0}\right) \leq \frac{C_{2}}{j^{\prime}} \text { and } P_{\left(i^{\prime}, j^{\prime}\right)}\left(D^{c}\right) \leq \frac{C_{3}}{i^{\prime}}+\frac{C_{4}}{j^{\prime}},
$$

for suitable positive constants $C_{2}, C_{3}$, and $C_{4}$. Furthermore, on $\left\{\mathrm{F}_{1} \leq \mathrm{M}_{1}\right\} \in \mathcal{F}_{1}$, the conditional distribution of $\mathrm{ZR}_{1}$ given $\mathcal{F}_{1}$ is hypergeometric. Hence, by following the same steps as given in the proof of Result 6 in González et al. (2009), one obtains for sufficiently large $i^{\prime}$ that

$$
\begin{aligned}
P_{\left(i^{\prime}, j^{\prime}\right)} & \left.D \cap\left\{\mathrm{ZR}_{1} \leq \eta_{1} \mathrm{ZR}_{0}, \mathrm{~F}_{1} \leq \mathrm{M}_{1}\right\}\right) \\
& =E_{\left(i^{\prime}, j^{\prime}\right)}\left[P_{\left(i^{\prime}, j^{\prime}\right)}\left(\mathrm{ZR}_{1} \leq \eta_{1} \mathrm{ZR}_{0} \mid \mathcal{F}_{1}\right) I_{D \cap\left\{\mathrm{F}_{1} \leq \mathrm{M}_{1}\right\}}\right] \\
& =E_{\left(i^{\prime}, j^{\prime}\right)}\left[P_{\left(i^{\prime}, j^{\prime}\right)}\left(\mathrm{ZR}_{1}-E_{\left(i^{\prime}, j^{\prime}\right)}\left[\mathrm{ZR}_{1} \mid \mathcal{F}_{1}\right] \leq \eta_{1} i^{\prime}-\frac{\mathrm{MR}_{1} \mathrm{~F}_{1}}{\mathrm{MR}_{1}+\mathrm{Mr}_{1}} \mid \mathcal{F}_{1}\right) I_{D \cap\left\{\mathrm{F}_{1} \leq \mathrm{M}_{1}\right\}}\right] \\
& \leq E_{\left(i^{\prime}, j^{\prime}\right)}\left[P_{\left(i^{\prime}, j^{\prime}\right)}\left(\mathrm{ZR}_{1}-E_{\left(i^{\prime}, j^{\prime}\right)}\left[\mathrm{ZR}_{1} \mid \mathcal{F}_{1}\right] \leq-\delta i^{\prime} \mid \mathcal{F}_{1}\right) I_{D \cap\left\{\mathrm{F}_{1} \leq \mathrm{M}_{1}\right\}}\right] \\
& \leq E_{\left(i^{\prime}, j^{\prime}\right)}\left[\exp \left(-2 \frac{\delta^{2} i^{\prime 2}-1}{\mathrm{MR}_{n}+1}\right) I_{D \cap\left\{\mathrm{F}_{1} \leq \mathrm{M}_{1}\right\}}\right] \\
& \leq \exp \left(-2 \frac{\delta^{2} i^{\prime 2}-1}{\gamma_{4} i^{\prime}+1}\right) \leq K_{1} e^{-B_{1} i^{\prime}}
\end{aligned}
$$

where $\delta=\alpha\left(\mathrm{m}_{\mathrm{R}}-\varepsilon\right) \varepsilon / \min \left\{\mathrm{m}_{\mathrm{R}}+\varepsilon, \mathrm{m}_{\mathrm{r}}+\varepsilon\right\}$ and $K_{1}, B_{1}$ are suitable positive constants. A similar estimation yields

$$
P_{\left(i^{\prime}, j^{\prime}\right)}\left(D \cap\left\{\mathrm{Zr}_{1} \leq \eta_{2} \mathrm{Zr}_{0}, \mathrm{~F}_{1} \leq \mathrm{M}_{1}\right\}\right) \leq K_{2} e^{-B_{2} j^{\prime}}
$$

for all sufficiently large $j^{\prime}$ and some positive constants $K_{2}$ and $B_{2}$. By combining (3)-(9), one finds that

$$
P_{\left(i^{\prime}, j^{\prime}\right)}\left(A_{0}\right)=1-P_{\left(i^{\prime}, j^{\prime}\right)}\left(A_{0}^{c}\right) \geq 1-\frac{C_{5}}{i^{\prime}}-\frac{C_{6}}{j^{\prime}}-K_{1} e^{-B_{1} i^{\prime}}-K_{2} e^{-B_{2} j^{\prime}},
$$

for some positive constants $C_{5}, C_{6}$ and sufficiently large $i^{\prime}, j^{\prime}$. Since $\eta_{1}, \eta_{2}>1$, it finally follows from (1) and (2) that

$$
\begin{aligned}
P_{(i, j)}\left(A_{\infty, \infty}\right) & \geq P_{(i, j)}\left(A_{0}\right) \lim _{n \rightarrow \infty} \prod_{l=1}^{n} \inf _{i^{\prime}>\eta_{1}^{l} i, j^{\prime}>\eta_{2}^{l} j} P_{\left(i^{\prime}, j^{\prime}\right)}\left(A_{0}\right) \\
& \geq P_{(i, j)}\left(A_{0}\right) \lim _{n \rightarrow \infty} \prod_{l=1}^{n}\left(1-\frac{C_{5}}{\eta_{1}^{l} i}-\frac{C_{6}}{\eta_{2}^{l} j}-K_{1} e^{-B_{1} \eta_{1}^{l} i}-K_{2} e^{-B_{2} \eta_{2}^{l} j}\right)>0
\end{aligned}
$$

for all sufficiently large $i, j$. But since all states with non-zero coordinates are communicating, one has in fact that $P_{(i, j)}\left(A_{\infty, \infty}\right)>0$ for all $i, j \geq 1$. This completes the proof. 


\subsection{Proof of Result 4.2}

The proof is furnished by the following three lemmata. The first two provide us with some useful martingales and supermartingales. We make the usual assumption that empty sums are defined as 0 .

Lemma 1 If $\mathrm{m}_{\mathrm{r}} \geq \mathrm{m}_{\mathrm{R}}$, then the sequence $\left(\mathrm{X}_{n}\right)_{n \geq 0}$, defined by

$$
\mathrm{X}_{n}=\frac{\mathrm{Z}_{n}}{\left(\alpha \mathrm{m}_{\mathrm{r}}\right)^{n}}+\frac{\mathrm{m}_{\mathrm{r}}-\mathrm{m}_{\mathrm{R}}}{\mathrm{m}_{\mathrm{r}}} \sum_{k=0}^{n-1} \frac{\mathrm{ZR}_{k}}{\left(\alpha \mathrm{m}_{\mathrm{r}}\right)^{k}}+\mathrm{U}_{n}, \quad n \geq 0,
$$

with

$$
\mathrm{U}_{n}=\sum_{k=1}^{n} \frac{E\left[\left(\mathrm{~F}_{k}-\mathrm{M}_{k}\right) I_{\left\{\mathrm{F}_{k}>\mathrm{M}_{k}\right\}} \mid \mathcal{G}_{k-1}\right]}{\left(\alpha \mathrm{m}_{\mathrm{r}}\right)^{k}}, \quad n \geq 0,
$$

constitutes a nonnegative martingale with respect to $\left(\mathcal{G}_{n}\right)_{n \geq 0}$ and converges a.s. to a finite random variable. Furthermore, there exists a nonnegative and finite random variable $\mathrm{W}$ such that

$$
\lim _{n \rightarrow \infty} \frac{\mathrm{Z}_{n}}{\left(\alpha \mathrm{m}_{\mathrm{r}}\right)^{n}}=\lim _{n \rightarrow \infty} \frac{\mathrm{ZR}_{n}+\mathrm{Zr}_{n}}{\left(\alpha \mathrm{m}_{\mathrm{r}}\right)^{n}}=\mathrm{W} \quad \text { a.s. }
$$

If $\mathrm{m}_{\mathrm{r}}>\mathrm{m}_{\mathrm{R}}$, then $\lim _{n \rightarrow \infty}\left(\alpha \mathrm{m}_{\mathrm{r}}\right)^{-n} \mathrm{ZR}_{n}=0$ a.s. and $\lim _{n \rightarrow \infty}\left(\alpha \mathrm{m}_{\mathrm{r}}\right)^{-n} \mathrm{Zr}_{n}=\mathrm{W}$ a.s.

Proof. A.s. convergence of $\left(\mathrm{X}_{n}\right)_{n \geq 0}$ follows from the Martingale Convergence Theorem once we have proved that this sequence is indeed a nonnegative martingale. To this end, let $B_{n}=\left\{\mathrm{F}_{n}<\mathrm{M}_{n}\right\}$ for $n \geq 0$. For each $n \geq 0$, one has

$$
\begin{aligned}
& E\left[\mathrm{X}_{n+1} \mid \mathcal{G}_{n}\right]=\frac{E\left[\mathrm{Z}_{n+1} \mid \mathcal{G}_{n}\right]}{\left(\alpha \mathrm{m}_{\mathrm{r}}\right)^{n+1}}+\frac{\mathrm{m}_{\mathrm{r}}-\mathrm{m}_{\mathrm{R}}}{\mathrm{m}_{\mathrm{r}}} \sum_{k=0}^{n} \frac{\mathrm{ZR}_{k}}{\left(\alpha \mathrm{m}_{\mathrm{r}}\right)^{k}}+\mathrm{U}_{n+1} \\
& =\frac{E\left[\mathrm{~F}_{n+1} I_{B_{n+1}}+\mathrm{M}_{n+1} I_{B_{n+1}^{c}} \mid \mathcal{G}_{n}\right]}{\left(\alpha \mathrm{m}_{\mathrm{r}}\right)^{n+1}}+\frac{\mathrm{m}_{\mathrm{r}}-\mathrm{m}_{\mathrm{R}}}{\mathrm{m}_{\mathrm{r}}} \sum_{k=0}^{n} \frac{\mathrm{ZR}_{k}}{\left(\alpha \mathrm{m}_{\mathrm{r}}\right)^{k}}+\mathrm{U}_{n+1} \\
& =\frac{E\left[\mathrm{~F}_{n+1} \mid \mathcal{G}_{n}\right]}{\left(\alpha \mathrm{m}_{\mathrm{r}}\right)^{n+1}}+\frac{\mathrm{m}_{\mathrm{r}}-\mathrm{m}_{\mathrm{R}}}{\mathrm{m}_{\mathrm{r}}} \sum_{k=0}^{n} \frac{\mathrm{ZR}_{k}}{\left(\alpha \mathrm{m}_{\mathrm{r}}\right)^{k}}+\mathrm{U}_{n} \\
& =\frac{\alpha\left(\mathrm{m}_{\mathrm{R}} \mathrm{ZR}_{n}+\mathrm{m}_{\mathrm{r}} \mathrm{Zr}_{n}\right)}{\left(\alpha \mathrm{m}_{\mathrm{r}}\right)^{n+1}}+\frac{\mathrm{m}_{\mathrm{r}}-\mathrm{m}_{\mathrm{R}}}{\mathrm{m}_{\mathrm{r}}} \sum_{k=0}^{n} \frac{\mathrm{ZR}_{k}}{\left(\alpha \mathrm{m}_{\mathrm{r}}\right)^{k}}+\mathrm{U}_{n} \\
& =\frac{Z_{n}}{\left(\alpha \mathrm{m}_{\mathrm{r}}\right)^{n}}-\frac{\left(\mathrm{m}_{\mathrm{r}}-\mathrm{m}_{\mathrm{R}}\right) \mathrm{ZR}_{n}}{\alpha^{n} \mathrm{~m}_{\mathrm{r}}^{n+1}}+\frac{\mathrm{m}_{\mathrm{r}}-\mathrm{m}_{\mathrm{R}}}{\mathrm{m}_{\mathrm{r}}} \sum_{k=0}^{n} \frac{\mathrm{ZR}_{k}}{\left(\alpha \mathrm{m}_{\mathrm{r}}\right)^{k}}+\mathrm{U}_{n} \quad \text { a.s. }
\end{aligned}
$$

and the last line clearly equals $\mathrm{X}_{n}$ which is obviously nonnegative.

The a.s. convergence of $\left(\alpha \mathrm{m}_{\mathrm{r}}\right)^{-n} \mathrm{Z}_{n}$ follows directly from the a.s. convergence of $\mathrm{X}_{n}$ and the fact that $\mathrm{X}_{n}-\left(\alpha \mathrm{m}_{\mathrm{r}}\right)^{-n} \mathrm{Z}_{n}$ equals the sum of two non-decreasing and thus convergent terms, the first of which even vanishes if $\mathrm{m}_{\mathrm{R}}=\mathrm{m}_{\mathrm{r}}$. If $\mathrm{m}_{\mathrm{r}}>\mathrm{m}_{\mathrm{R}}$, then $\sum_{k \geq 0}\left(\alpha \mathrm{m}_{\mathrm{r}}\right)^{-k} \mathrm{ZR}_{k}<\infty$ a.s. and thus $\left(\alpha \mathrm{m}_{\mathrm{r}}\right)^{-n} \mathrm{ZR}_{n} \rightarrow 0$ a.s.

Lemma 2 The sequences $\left(\mathrm{Y}_{n}^{\mathrm{R}}\right)_{n \geq 1}$ and $\left(\mathrm{Y}_{n}^{\mathrm{r}}\right)_{n \geq 1}$, defined by

$$
\mathrm{Y}_{n}^{\mathrm{x}}=I_{\left\{\mathrm{F}_{n}>0\right\}}\left[\prod_{k=1}^{n}\left(\frac{\mathrm{M}_{k}}{\mathrm{~F}_{k}} \vee 1\right)\right] \frac{\mathrm{Z} \mathrm{x}_{n}}{\left((1-\alpha) \mathrm{m}_{\mathrm{x}}\right)^{n}}, \quad n \geq 1
$$

for $\mathrm{x} \in\{\mathrm{R}, \mathrm{r}\}$, where $a \vee b:=\max \{a, b\}$, are both nonnegative supermartingales with respect to $\left(\mathcal{G}_{n}\right)_{n \geq 0}$ and thus a.s. convergent to nonnegative random variables. 
Proof. It suffices to verify the supermartingale property. Let $B_{n}$ be defined as in the previous proof and put

$$
\mathrm{R}_{n}=\left[\frac{\mathrm{M}_{n}}{\mathrm{~F}_{n}} \vee 1\right] I_{\left\{\mathrm{F}_{n}>0\right\}} \quad \text { for } n \geq 1
$$

Since $\left\{\mathrm{F}_{n+1}>0\right\} \subseteq\left\{\mathrm{F}_{n}>0\right\}$ for all $n \geq 1$, it follows for any $\mathrm{x} \in\{\mathrm{R}, \mathrm{r}\}$ and $n \geq 1$ that

$$
\begin{aligned}
E\left[\mathrm{Y}_{n+1}^{\times} \mid \mathcal{G}_{n}\right] & =\frac{1}{\left((1-\alpha) \mathrm{m}_{\times}\right)^{n+1}}\left[\prod_{k=1}^{n} R_{k}\right] E\left[\mathrm{R}_{n+1} E\left[\mathrm{ZR}_{n+1} \mid \mathcal{F}_{n+1}\right] \mid \mathcal{G}_{n}\right] \\
& =\frac{1}{\left((1-\alpha) \mathrm{m}_{\times}\right)^{n+1}}\left[\prod_{k=1}^{n} \mathrm{R}_{k}\right] E\left[\mathrm{R}_{n+1}\left(\frac{\mathrm{F}_{n+1} \mathrm{MR}_{n+1}}{\mathrm{M}_{n+1}} I_{B_{n+1}}+\mathrm{MR}_{n+1} I_{B_{n+1}^{c}}\right) \mid \mathcal{G}_{n}\right] \\
& =\frac{1}{\left((1-\alpha) \mathrm{m}_{\times}\right)^{n+1}}\left[\prod_{k=1}^{n} \mathrm{R}_{k}\right]\left(E\left[\mathrm{MR}_{n+1} \mid \mathcal{G}_{n}\right]-E\left[\mathrm{MR}_{n+1} I_{\left\{\mathrm{F}_{n+1}=0\right\}} \mid \mathcal{G}_{n}\right]\right) \\
& \leq \frac{1}{\left((1-\alpha) \mathrm{m}_{\mathbf{x}}\right)^{n+1}}\left[\prod_{k=1}^{n} \mathrm{R}_{k}\right] E\left[\mathrm{MR}_{n+1} \mid \mathcal{G}_{n}\right] \\
& =\frac{1}{\left((1-\alpha) \mathrm{m}_{\times}\right)^{n}}\left[\prod_{k=1}^{n} \mathrm{R}_{k}\right] \mathrm{ZR}_{n} \text { a.s., }
\end{aligned}
$$

which proves the asserted supermartingale property.

The last lemma shows that the ratio of the total number of females to the total number of males in each generation equals $\alpha /(1-\alpha)$ if both genotypes survive and the growth rate of the total number of couples over one generation is ultimately greater than unity. It holds under no further assumptions on $\alpha, \alpha \mathrm{m}_{\mathrm{R}}$ or $\alpha \mathrm{m}_{\mathrm{r}}$. In its proof, we will make use of the following simple analytic fact.

Fact. If $\left(a_{n}\right)_{n \geq 0}$ and $\left(b_{n}\right)_{n \geq 0}$ are two sequences of positive numbers such that $b_{n} \rightarrow 0$ and $a_{n}=a+O\left(b_{n}\right)$ for some $a>0$ and $n \rightarrow \infty$, then $a_{n}^{-1}=a^{-1}+O\left(b_{n}\right)$.

Lemma 3 If $A:=\left\{\liminf _{n \rightarrow \infty} Z_{n}^{-1} Z_{n+1}>1\right\} \cap A_{\infty, \infty}$ has positive probability, then for each $0<\rho<1 / 2$

$$
\frac{\mathrm{F}_{n+1}}{\mathrm{M}_{n+1}}=\frac{\alpha}{1-\alpha}+O\left(\mathrm{Z}_{n}^{-\rho}\right) \quad \text { a.s. on } A \text {, as } n \rightarrow \infty \text {. }
$$

Proof. On $A_{\infty, \infty}$, one can write

$$
\frac{\mathrm{F}_{n+1}}{\mathrm{M}_{n+1}}=\frac{\mathrm{F}_{n+1}}{\mathrm{~m}_{\mathrm{R}} \mathrm{ZR}_{n}+\mathrm{m}_{\mathrm{r}} \mathrm{Zr}_{n}} \frac{\mathrm{m}_{\mathrm{R}} \mathrm{ZR}_{n}+\mathrm{m}_{\mathrm{r}} \mathrm{Zr}_{n}}{\mathrm{M}_{n+1}}
$$

Then, by the above fact, it is enough to prove that, as $n \rightarrow \infty$,

$$
\frac{\mathrm{M}_{n+1}}{\mathrm{~m}_{\mathrm{R}} \mathrm{ZR}_{n}+\mathrm{m}_{\mathrm{r}} \mathrm{Zr}_{n}}=1-\alpha+O\left(\mathrm{Z}_{n}^{-\rho}\right) \quad \text { and } \quad \frac{\mathrm{F}_{n+1}}{\mathrm{~m}_{\mathrm{R}} \mathrm{ZR}_{n}+\mathrm{m}_{\mathrm{r}} \mathrm{Zr}_{n}}=\alpha+O\left(\mathrm{Z}_{n}^{-\rho}\right)
$$

a.s. on $A_{\infty, \infty}$. We shall only prove the first asymptotic relation because the second one follows analogously. Fix any $0<\rho<1 / 2$ and define

$$
A_{n}=\left\{\left|\mathrm{M}_{n+1}-\left((1-\alpha) \mathrm{m}_{\mathrm{R}} \mathrm{ZR}_{n}+(1-\alpha) \mathrm{m}_{\mathrm{r}} \mathrm{Zr}_{n}\right)\right| \geq \mathrm{Z}_{n}^{-\rho}\left(\mathrm{m}_{\mathrm{R}} \mathrm{ZR}_{n}+\mathrm{m}_{\mathrm{r}} \mathrm{Zr}_{n}\right)\right\}
$$

for $n \geq 0$. Applying Chebyshev's inequality, it follows that, for some positive constant $C$,

$$
\sum_{n=0}^{\infty} P\left(A_{n} \mid \mathcal{G}_{n}\right) \leq \sum_{n=0}^{\infty} \frac{\operatorname{Var}\left(\mathrm{M}_{n+1} \mid \mathcal{G}_{n}\right)}{\mathrm{Z}_{n}^{-2 \rho}\left(\mathrm{m}_{\mathrm{R}} \mathrm{ZR}_{n}+\mathrm{m}_{\mathrm{r}} \mathrm{Zr}_{n}\right)^{2}} \leq C \sum_{n=0}^{\infty} \frac{1}{\mathrm{Z}_{n}^{1-2 \rho}}<\infty \text { a.s. on } A_{\infty, \infty}
$$


where we have also used that $\operatorname{Var}\left(\mathrm{M}_{n+1} \mid \mathcal{G}_{n}\right) \leq C\left(\mathrm{~m}_{\mathrm{R}} \mathrm{ZR}_{n}+\mathrm{m}_{\mathrm{r}} \mathrm{Zr}_{n}\right)$ a.s. for all $n \geq 0$. Therefore, the conditional Borel-Cantelli lemma yields

$$
A_{\infty, \infty} \subseteq\left\{\sum_{n=0}^{\infty} P\left(A_{n} \mid \mathcal{G}_{n}\right)<\infty\right\}=\liminf _{n \rightarrow \infty}\left\{\left|\frac{\mathrm{M}_{n+1}}{\mathrm{~m}_{\mathrm{R}} \mathrm{ZR}_{n}+\mathrm{m}_{\mathrm{r}} \mathrm{Zr}_{n}}-(1-\alpha)\right|<\mathrm{Z}_{n}^{-\rho}\right\} \quad \text { a.s. }
$$

and this gives the desired result.

\section{Proof of Result 4.2}

It suffices to consider the case $\alpha<0.5, \alpha \mathrm{m}_{\mathrm{R}}=1<\alpha \mathrm{m}_{\mathrm{r}}$ (thus $\tau=\alpha \mathrm{m}_{\mathrm{r}}$ ) because the other case follows in the same way. Further, let $P\left(A_{\infty, \infty}\right)$ be positive, for otherwise there is nothing to verify. Lemma 1 ensures the existence of a nonnegative and finite random variable $\mathrm{W}$ such that

$$
\lim _{n \rightarrow \infty} \frac{\mathrm{ZR}_{n}+\mathrm{Zr}_{n}}{\tau^{n}}=\lim _{n \rightarrow \infty} \frac{\mathrm{Zr}_{n}}{\tau^{n}}=\mathrm{W} \text { and } \lim _{n \rightarrow \infty} \frac{\mathrm{ZR}_{n}}{\tau^{n}}=0 \text { a.s. }
$$

Now consider $A_{\rho}:=\left\{\liminf _{n \rightarrow \infty} \rho^{-n} \mathbf{Z}_{n}>0\right\} \cap A_{\infty, \infty}$ for $\rho \in(1, \tau]$ and observe that $\liminf \operatorname{in}_{n \rightarrow \infty} \mathbf{Z}_{n}^{-1} \mathbf{Z}_{n+1}>$ 1 a.s. on this event. If $P\left(A_{\rho}\right)>0$, then Lemma 3 implies that

$$
0<\prod_{k=1}^{\infty}\left(\frac{\alpha \mathrm{M}_{k}}{(1-\alpha) \mathrm{F}_{k}} \vee \frac{\alpha}{1-\alpha}\right)<\infty \text { a.s. on } A_{\rho} \text {. }
$$

Rewrite $\mathrm{Y}_{n}^{\mathrm{R}}$ from Lemma 2 in the form

$$
\mathrm{Y}_{n}^{\mathrm{R}}=I_{\left\{\mathrm{F}_{n}>0\right\}}\left[\prod_{k=1}^{n}\left(\frac{\alpha \mathrm{M}_{k}}{(1-\alpha) \mathrm{F}_{k}} \vee \frac{\alpha}{1-\alpha}\right)\right] \frac{\mathrm{ZR}_{n}}{\left(\alpha \mathrm{m}_{\mathrm{R}}\right)^{n}}, \quad n \geq 0,
$$

in order to infer from this lemma in combination with (11) that

$$
\lim _{n \rightarrow \infty} \frac{\mathrm{ZR}_{n}}{\left(\alpha \mathrm{m}_{\mathrm{R}}\right)^{n}}=\lim _{n \rightarrow \infty} \mathrm{ZR}_{n}<\infty \quad \text { a.s. on } A_{\rho}
$$

which is a contradiction because $\mathrm{ZR}_{n}$ must a.s. tend to infinity on $A_{\infty, \infty}$. Consequently, $P\left(A_{\rho}\right)=0$ for each $\rho \in(1, \tau]$, in particular $\mathrm{W}=0$ a.s. on $A_{\infty, \infty}$.

\subsection{Proof of Result 5.1}

Again, we start by proving a number of preparative lemmata. The first one shows that in the event of survival of both genotypes the growth rate of the number of $x$-couples over one generation is ultimately greater than unity for each $x \in\{R, r\}$.

Lemma 4 If $\alpha \leq 0.5$ and $\min \left\{\alpha \mathrm{m}_{\mathrm{R}}, \alpha \mathrm{m}_{\mathrm{r}}\right\}>1$ or $\alpha>0.5$ and $\min \left\{(1-\alpha) \mathrm{m}_{\mathrm{R}},(1-\alpha) \mathrm{m}_{\mathrm{r}}\right\}>1$, then

$$
\liminf _{n \rightarrow \infty} \frac{\mathrm{ZR}_{n+1}}{\mathrm{ZR}_{n}}>1 \quad \text { and } \quad \liminf _{n \rightarrow \infty} \frac{\mathrm{Zr}_{n+1}}{\mathrm{Zr}_{n}}>1 \quad \text { a.s. on } A_{\infty, \infty} \text {. }
$$

Proof. Let $\eta_{1}, \eta_{2}>1$ and $A_{n}=\left\{\mathrm{ZR}_{n+1}>\eta_{1} \mathrm{ZR}_{n}, \mathrm{Zr}_{n+1}>\eta_{2} \mathrm{Zr}_{n}\right\}$ for $n \geq 0$. It is enough to prove that, for some $\eta_{1}, \eta_{2}$,

$$
P\left(\liminf _{n \rightarrow \infty} A_{n}\right) \geq P\left(A_{\infty, \infty}\right)
$$

because $\lim \inf _{n \rightarrow \infty} A_{n} \subseteq A_{\infty, \infty}$ and the previous inequality implies that $\liminf _{n \rightarrow \infty} A_{n}=A_{\infty, \infty}$ a.s. To this end, we define for each $N \geq 1$ the stopping time $T(N)=\min \left\{n: \mathrm{ZR}_{n} \wedge \operatorname{Zr}_{n} \geq N\right\}$, where $T(N)=\infty$ if $\mathrm{ZR}_{n} \wedge \mathrm{Zr}_{n}<N$ for all $n \geq 0$. Obviously

$$
A_{\infty, \infty} \subseteq\{T(N)<\infty\}
$$


for each $N$, and

$$
\{T(N)=k\}=\left\{\mathrm{ZR}_{k} \geq N, \mathrm{Zr}_{k} \geq N, \mathrm{ZR}_{n} \wedge \mathrm{Zr}_{n}<N, n=0, \ldots, k-1\right\}, \quad k \geq 1 .
$$

Since $\left(\mathrm{ZR}_{n}, \mathrm{Zr}_{n}\right)_{n \geq 0}$ forms a homogeneous Markov chain, then

$$
P\left(\bigcap_{n=k}^{\infty} A_{n} \mid T(N)=k\right)=P\left(\bigcap_{n=k}^{\infty} A_{n} \mid \mathrm{ZR}_{k} \geq N, \mathrm{Zr}_{k} \geq N\right) \geq \inf _{i, j \geq N} P_{(i, j)}\left(\bigcap_{n=0}^{\infty} A_{n}\right)
$$

and therefore, by applying (13), one deduces that for every $N$

$$
\begin{aligned}
P\left(\liminf _{n \rightarrow \infty} A_{n}\right) & \geq \sum_{k=0}^{\infty} P\left(\bigcap_{n=k}^{\infty} A_{n} \mid T(N)=k\right) P(T(N)=k) \\
& \geq \inf _{i, j \geq N} P_{(i, j)}\left(\bigcap_{n=0}^{\infty} A_{n}\right) P\left(A_{\infty, \infty}\right) .
\end{aligned}
$$

Hence, to obtain (12), it suffices to prove the existence of $\eta_{1}, \eta_{2}>1$ such that

$$
\lim _{i, j \rightarrow \infty} P_{(i, j)}\left(\bigcup_{n=0}^{\infty} A_{n}^{c}\right)=0 .
$$

This last union of sets can be rewritten as the union of the disjoint sets $B_{n}$ defined by

$$
B_{0}=A_{0}^{c}, \quad B_{n}=A_{n}^{c} \cap A_{n-1} \cap \cdots \cap A_{0}, \quad n \geq 1,
$$

and we are thus going to prove the existence of $\eta_{1}, \eta_{2}>1$ such that

$$
\lim _{i, j \rightarrow \infty} \sum_{n=0}^{\infty} P_{(i, j)}\left(B_{n}\right)=0
$$

For all $n \geq 1$, the probability of $B_{n}$ can be calculated as

$$
P_{(i, j)}\left(B_{n}\right)=E_{(i, j)}\left[I_{A_{n-1} \cap \cdots \cap A_{0}} P\left(A_{n}^{c} \mid \mathcal{G}_{n}\right)\right]
$$

so that a convenient bound needs to be found for $P\left(A_{n}^{c} \mid \mathcal{G}_{n}\right)$. Given $\alpha=0.5$ and $\min \left\{\alpha \mathrm{m}_{\mathrm{R}}, \alpha \mathrm{m}_{\mathrm{r}}\right\}>1$, we infer from (10) that there exist $\eta_{1}, \eta_{2}>1$ such that

$$
P\left(A_{n}^{c} \mid \mathcal{G}_{n}\right) \leq \frac{C_{1}}{\mathrm{ZR}_{n}}+\frac{C_{2}}{\mathrm{Zr}_{n}}+C_{3} e^{-C_{4} \mathrm{ZR}_{n}}+C_{5} e^{-C_{6} \mathrm{Zr}_{n}} \quad \text { a.s. on }\left\{\mathrm{ZR}_{n} \wedge \mathrm{Zr}_{n}>M\right\},
$$

for suitable positive constants $C_{1}, C_{2}, C_{3}, C_{4}, C_{5}, C_{6}$, and $M$. This inequality continues to hold under $\alpha<0.5$ and $\min \left\{\alpha \mathrm{m}_{\mathrm{R}}, \alpha \mathrm{m}_{\mathrm{r}}\right\}>1$, as was shown in the proof of Result 6 in González et al. (2009). Moreover, if $\alpha>0.5$ and $\min \left\{(1-\alpha) \mathrm{m}_{\mathrm{R}},(1-\alpha) \mathrm{m}_{\mathrm{r}}\right\}>1$, it was also shown there that there exist $\eta_{1}, \eta_{2}>1$ such that

$$
P\left(A_{n}^{c} \mid \mathcal{G}_{n}\right) \leq \frac{C_{7}}{\mathrm{ZR}_{n}}+\frac{C_{8}}{\mathrm{Zr}_{n}}+f_{\mathrm{R}}(a)^{\mathrm{ZR}_{n}}+f_{\mathrm{r}}(a)^{\mathrm{Zr}_{n}} \quad \text { a.s. on }\left\{\mathrm{ZR}_{n} \wedge \mathrm{Zr}_{n}>0\right\},
$$

for suitable $C_{7}, C_{8}>0$, and $0<a<1$, where $f_{\mathrm{x}}(\cdot)$ denotes the probability generating function of the x-type reproduction law for $\mathrm{x} \in\{\mathrm{R}, \mathrm{r}\}$. Having $\mathrm{ZR}_{n} \geq \eta_{1}^{n} \mathrm{ZR}_{0}$ and $\mathrm{Zr}_{n} \geq \eta_{2}^{n} \mathrm{Zr}_{0}$ on $A_{n-1} \cap \cdots \cap A_{0}$, it thus follows that, regardless of the value of $\alpha$, there exist constants $K_{1}, K_{2}, K_{3}, K_{4}>0$ and $0<a_{1}, a_{2}<1$ such that

$$
E_{(i, j)}\left[I_{A_{n-1} \cap \cdots \cap A_{0}} P\left(A_{n}^{c} \mid \mathcal{G}_{n}\right)\right] \leq \frac{K_{1}}{i \eta_{1}^{n}}+\frac{K_{2}}{j \eta_{2}^{n}}+K_{3} a_{1}^{i \eta_{1}^{n}}+K_{4} a_{2}^{j \eta_{2}^{n}}
$$

whence

$$
\sum_{n=0}^{\infty} P_{(i, j)}\left(B_{n}\right) \leq \frac{K_{1}}{i} \sum_{n=0}^{\infty} \eta_{1}^{-n}+\frac{K_{2}}{j} \sum_{n=0}^{\infty} \eta_{2}^{-n}+K_{3} \sum_{n=0}^{\infty} a_{1}^{i \eta_{1}^{n}}+K_{4} \sum_{n=0}^{\infty} a_{2}^{j \eta_{2}^{n}}
$$


Since $\eta_{1}, \eta_{2}>1$, the two first series are convergent and the accompanying factors converge to 0 as $i$ and $j$ tend to $\infty$. By the dominated convergence theorem, the two other terms also tend to 0 as $i$ and $j$ tend to $\infty$. This completes the proof.

Our second lemma describes, for each genotype, the asymptotic behaviour of the ratio between the number of males, respectively females, and the number of couples in the previous generation given that simultaneous survival occurs.

Lemma 5 If $\alpha \leq 0.5$ and $\min \left\{\alpha \mathrm{m}_{\mathrm{R}}, \alpha \mathrm{m}_{\mathrm{r}}\right\}>1$, or $\alpha>0.5$ and $\min \left\{(1-\alpha) \mathrm{m}_{\mathrm{R}},(1-\alpha) \mathrm{m}_{\mathrm{r}}\right\}>1$, then for each $0<\rho<1 / 2$

$$
\begin{gathered}
\frac{\mathrm{MR}_{n+1}}{\mathrm{ZR}_{n}}=(1-\alpha) \mathrm{m}_{\mathrm{R}}+O\left(\mathrm{ZR}_{n}^{-\rho}\right), \quad \frac{\mathrm{Mr}_{n+1}}{\mathrm{Zr}_{n}}=(1-\alpha) \mathrm{m}_{\mathrm{r}}+O\left(\mathrm{Zr}_{n}^{-\rho}\right), \\
\frac{\mathrm{FR}_{n+1}}{\mathrm{ZR}_{n}}=\alpha \mathrm{m}_{\mathrm{R}}+O\left(\mathrm{ZR}_{n}^{-\rho}\right) \quad \text { and } \quad \frac{\mathrm{Fr}_{n+1}}{\mathrm{Zr}_{n}}=\alpha \mathrm{m}_{\mathrm{r}}+O\left(\mathrm{Zr}_{n}^{-\rho}\right) \quad \text { a.s. on } A_{\infty, \infty}
\end{gathered}
$$

as $n \rightarrow \infty$.

Proof. Since all four assertions are obtained in a similar manner, we confine ourselves to a proof of the first. For $n \geq 0$, define

$$
A_{n}=\left\{\left|\mathrm{MR}_{n+1}-(1-\alpha) \mathrm{m}_{\mathrm{R}} \mathrm{ZR}_{n}\right| \geq \mathrm{ZR}_{n}^{1-\rho}\right\} .
$$

By an appeal to Chebyshev's inequality and Lemma 4 , we infer

$$
\sum_{n=0}^{\infty} P\left(A_{n} \mid \mathcal{G}_{n}\right) \leq \sum_{n=0}^{\infty} \frac{\operatorname{Var}\left(\mathrm{MR}_{n+1} \mid \mathcal{G}_{n}\right)}{\mathrm{ZR}_{n}^{2(1-\rho)}} \leq C \sum_{n=0}^{\infty} \frac{1}{\mathrm{ZR}_{n}^{1-2 \rho}}<\infty \text { a.s. on } A_{\infty, \infty}
$$

for some positive constant $C$. Hence, by the conditional Borel-Cantelli lemma,

$$
A_{\infty, \infty} \subseteq\left\{\sum_{n=0}^{\infty} P\left(A_{n} \mid \mathcal{G}_{n}\right)<\infty\right\}=\liminf _{n \rightarrow \infty}\left\{\left|\frac{\mathrm{MR}_{n+1}}{\mathrm{ZR}_{n}}-(1-\alpha) \mathrm{m}_{\mathrm{R}}\right|<\mathrm{ZR}_{n}^{-\rho}\right\} \quad \text { a.s. }
$$

which is the desired conclusion.

Our last lemma shows that, if simultaneous survival occurs and $\alpha \neq 0.5$, then for each type, either the number of females of a generation will eventually exceed the number of respective males, or vice versa, depending on whether $\alpha$ is greater or less than 0.5 .

\section{Lemma 6}

(i) If $\alpha<0.5$ and $\min \left\{\alpha \mathrm{m}_{\mathrm{R}}, \alpha \mathrm{m}_{\mathrm{r}}\right\}>1$, then

$$
A_{\infty, \infty}=\left\{\mathrm{FR}_{n}<\mathrm{MR}_{n}, \mathrm{Fr}_{n}<\mathrm{Mr}_{n} \text { eventually }\right\} \quad \text { a.s. }
$$

(ii) If $\alpha>0.5$ and $\min \left\{(1-\alpha) \mathrm{m}_{\mathrm{R}},(1-\alpha) \mathrm{m}_{\mathrm{r}}\right\}>1$, then

$$
A_{\infty, \infty}=\left\{\mathrm{FR}_{n}>\mathrm{MR}_{n}, \mathrm{Fr}_{n}>\mathrm{Mr}_{n} \text { eventually }\right\} \text { a.s. }
$$

Proof. We shall only prove (i) because assertion (ii) is obtained in the same manner. But if $\alpha<0.5$ and $\min \left\{\alpha \mathrm{m}_{\mathrm{R}}, \alpha \mathrm{m}_{\mathrm{r}}\right\}>1$, then Lemma 5 gives

$$
\lim _{n \rightarrow \infty} \frac{\mathrm{FR}_{n}}{\mathrm{MR}_{n}}=\lim _{n \rightarrow \infty} \frac{\mathrm{Fr}_{n}}{\mathrm{Mr}_{n}}=\frac{\alpha}{1-\alpha}<1 \text { a.s. on } A_{\infty, \infty}
$$

which completes the proof. 


\section{Proof of Result 5.1}

Again we confine ourselves to the case of R-couples. Since $\alpha>0.5$ and $\min \left\{(1-\alpha) \mathrm{m}_{\mathrm{R}},(1-\alpha) \mathrm{m}_{\mathrm{r}}\right\}>1$, we deduce with the help of Lemma 6 and using the definition of the model that $A_{\infty, \infty}=\left\{\mathrm{ZR}_{n}=\mathrm{MR}_{n}, \mathrm{Zr}_{n}=\right.$ $\mathrm{Mr}_{n}$ eventually\} a.s. As a consequence, Lemma 5 ensures that, as $n \rightarrow \infty$,

$$
\frac{\mathrm{ZR}_{n+1}}{\mathrm{ZR}_{n}}=(1-\alpha) \mathrm{m}_{\mathrm{R}}+O\left(\mathrm{ZR}_{n}^{-\rho}\right) \quad \text { a.s. on } A_{\infty, \infty}
$$

for each $0<\rho<1 / 2$. Now observe that, for each $N \geq 1$,

$$
\frac{\mathrm{ZR}_{N}}{\left((1-\alpha) \mathrm{m}_{\mathrm{R}}\right)^{N}}=\mathrm{ZR}_{0} \prod_{n=0}^{N-1} \frac{\mathrm{ZR}_{n+1}}{(1-\alpha) \mathrm{m}_{\mathrm{R}} \mathrm{ZR}_{n}}
$$

to infer upon using (14), Lemma 4, and Theorem 7.28 in Stromberg (1981) that

$$
0<\prod_{n=0}^{\infty} \frac{\mathrm{ZR}_{n+1}}{(1-\alpha) \mathrm{m}_{\mathrm{R}} \mathrm{ZR}_{n}}<\infty \quad \text { a.s. on } A_{\infty, \infty}
$$

and thus $0<\mathrm{W}_{\mathrm{R}}:=\lim _{n \rightarrow \infty}\left((1-\alpha) \mathrm{m}_{\mathrm{R}}\right)^{n} \mathrm{ZR}_{n}<\infty$ a.s. on $A_{\infty, \infty}$. Replacing $\mathrm{ZR}_{n}$ with $\mathrm{MR}_{n}$, the same result holds true, since

$$
\lim _{n \rightarrow \infty} \frac{\mathrm{MR}_{n}}{\mathrm{ZR}_{n-1}}=(1-\alpha) \mathrm{m}_{\mathrm{R}} \quad \text { a.s. on } A_{\infty}, \infty
$$

by Lemma 5 . All the remaining assertions are obtained in a similar manner.

\subsection{Proof of Result 5.2}

Here two auxiliary lemmata are needed. For positive integers $i_{\mathrm{R}}, i_{\mathrm{r}}, j, k$ and $\mathrm{x} \in\{\mathrm{R}, \mathrm{r}\}$, define

$$
\mu_{\mathrm{x}}\left(i_{\mathrm{R}}, j, i_{\mathrm{r}}, k\right):=\frac{E\left[\mathrm{Zx}_{n} \mid \mathrm{MR}_{n}=i_{\mathrm{R}}, \mathrm{FR}_{n}=j, \mathrm{Mr}_{n}=i_{\mathrm{r}}, \mathrm{Fr}_{n}=k\right]}{i_{\mathrm{x}}} .
$$

Lemma 7 For each $n \geq 1$ and $x \in\{\mathrm{R}, \mathrm{r}\}$,

$$
\mu_{\times}\left(\mathrm{MR}_{n}, \mathrm{FR}_{n}, \mathrm{Mr}_{n}, \mathrm{Fr}_{n}\right)=\left\{\begin{array}{ll}
\mathrm{F}_{n} / \mathrm{M}_{n}, & \text { if } \mathrm{F}_{n} \leq \mathrm{M}_{n} \\
1, & \text { otherwise }
\end{array} \text { a.s. on } A_{\infty, \infty}\right.
$$

Proof. It suffices to note the following fact, valid for each $\mathrm{x} \in\{\mathrm{R}, \mathrm{r}\}$. If $\mathrm{F}_{n}>\mathrm{M}_{n}$, then $Z \mathrm{x}_{n}=\mathrm{Mx}_{n}$, while $\mathrm{F}_{n} \leq \mathrm{M}_{n}$ implies that the conditional law of $\mathrm{Zx}_{n}$ given $\mathrm{MR}_{n}, \mathrm{FR}_{n}, \mathrm{Mr}_{n}, \mathrm{Fr}_{n}$ is hypergeometric with parameters $\mathrm{F}_{n}, \mathrm{M}_{n}, \mathrm{Mx}_{n}$, thus $E\left[\mathrm{Zx}_{n} \mid \mathrm{MR}_{n}, \mathrm{FR}_{n}, \mathrm{Mr}_{n}, \mathrm{Fr}_{n}\right]=\frac{\mathrm{F}_{n}}{\mathrm{M}_{n}} \mathrm{Mx}_{n}$ a.s.

The second lemma shows that, for each genotype, the asymptotic ratio between the number of couples and males of a generation equals $\alpha / 1-\alpha$, when both genotypes survive. The reader should notice that this result differs slightly from the corresponding assertion in Lemma 5 which compares the number of couples of a generation to the number of males in the next generation.

Lemma 8 If $\alpha \leq 0.5$ and $\min \left\{\alpha \mathrm{m}_{\mathrm{R}}, \alpha \mathrm{m}_{\mathrm{r}}\right\}>1$, then, as $n \rightarrow \infty$,

$$
\frac{\mathrm{ZR}_{n}}{\mathrm{MR}_{n}}=\frac{\alpha}{1-\alpha}+O\left(\mathrm{ZR}_{n-1}^{-\rho}\right) \quad \text { and } \quad \frac{\mathrm{Zr}_{n}}{\mathrm{Mr}_{n}}=\frac{\alpha}{1-\alpha}+O\left(\mathrm{Zr}_{n-1}^{-\rho}\right) \quad \text { a.s. on } A_{\infty, \infty}
$$

for each $0<\rho<1 / 2$. 
Proof. Again considering only the R-genotype, it is enough to prove that, as $n \rightarrow \infty$,

$$
\frac{\mathrm{ZR}_{n}}{\mathrm{MR}_{n}}=\mu_{\mathrm{R}}\left(\mathrm{MR}_{n}, \mathrm{FR}_{n}, \mathrm{Mr}_{n}, \mathrm{Fr}_{n}\right)+O\left(\mathrm{ZR}_{n-1}^{-\rho}\right) \quad \text { a.s. on } A_{\infty, \infty}
$$

and

$$
\mu_{\mathrm{R}}\left(\mathrm{MR}_{n}, \mathrm{FR}_{n}, \mathrm{Mr}_{n}, \mathrm{Fr}_{n}\right)=\frac{\alpha}{1-\alpha}+O\left(\mathrm{ZR}_{n-1}^{-\rho}\right) \quad \text { a.s. on } A_{\infty, \infty}
$$

for each $0<\rho<1 / 2$. By Lemma $4, \mathrm{ZR}_{n-1}<\mathrm{ZR}_{n}$ eventually a.s. on $A_{\infty, \infty}$. Since $\mathrm{ZR}_{n} \leq \mathrm{MR}_{n}$ for all $n \geq 0$, (15) follows if we prove that

$$
\frac{\mathrm{ZR}_{n}}{\mathrm{MR}_{n}}=\mu_{\mathrm{R}}\left(\mathrm{MR}_{n}, \mathrm{FR}_{n}, \mathrm{Mr}_{n}, \mathrm{Fr}_{n}\right)+O\left(\mathrm{MR}_{n}^{-\rho}\right) \quad \text { a.s. on } A_{\infty, \infty} \text {. }
$$

To this end, we use Chebyshev's inequality to infer

$$
P\left(\left|\mathrm{ZR}_{n}-E\left[\mathrm{ZR}_{n} \mid \mathcal{F}_{n}\right]\right| \geq \mathrm{MR}_{n}^{1-\rho} \mid \mathcal{F}_{n}\right) \leq \frac{\operatorname{Var}\left(\mathrm{ZR}_{n} \mid \mathcal{F}_{n}\right)}{\mathrm{MR}_{n}^{2(1-\rho)}} \quad \text { a.s. on } A_{\infty, \infty}
$$

for each $0<\rho<1 / 2$ and $n \geq 0$. Next observe that, a.s. on $A_{\infty, \infty}$

$$
\operatorname{Var}\left(\mathrm{ZR}_{n} \mid \mathcal{F}_{n}\right)= \begin{cases}0, & \text { if } \mathrm{F}_{n}>\mathrm{M}_{n} \\ \left(\frac{\mathrm{F}_{n}}{\mathrm{M}_{n}} \mathrm{MR}_{n}\right)\left(\frac{\mathrm{Mr}_{n}}{\mathrm{M}_{n}}\right)\left(\frac{\mathrm{M}_{n}-\mathrm{F}_{n}}{\mathrm{M}_{n}-1}\right), & \text { if } \mathrm{F}_{n} \leq \mathrm{M}_{n}\end{cases}
$$

giving $\operatorname{Var}\left(\mathrm{ZR}_{n} \mid \mathcal{F}_{n}\right) \leq \mathrm{MR}_{n}$ a.s. on $A_{\infty, \infty}$, because $\mathrm{M}_{n}-\mathrm{F}_{n} \leq \mathrm{M}_{n}-1$ on $\left\{\mathrm{F}_{n}>0\right\}$ and $\mathrm{Mr}_{n} \leq \mathrm{M}_{n}$. Hence, by invoking Lemma 4, one obtains

$$
\sum_{n=0}^{\infty} P\left(\left|\mathrm{ZR}_{n}-E\left[\mathrm{ZR}_{n} \mid \mathcal{F}_{n}\right]\right| \geq \mathrm{MR}_{n}^{1-\rho} \mid \mathcal{F}_{n}\right) \leq \sum_{n=0}^{\infty} \frac{1}{\mathrm{MR}_{n}^{1-2 \rho}} \leq \sum_{n=0}^{\infty} \frac{1}{\mathrm{ZR}_{n}^{1-2 \rho}}<\infty \text { a.s. on } A_{\infty, \infty}
$$

This gives (17) by the conditional Borel-Cantelli lemma because the sets $A_{\infty, \infty} \cap\left\{\left|Z_{n}-E\left[Z_{n} \mid \mathcal{F}_{n}\right]\right| \geq\right.$ $\left.\mathrm{MR}_{n}^{1-\rho}\right\}$ and

$$
A_{\infty, \infty} \cap\left\{\left|\frac{\mathrm{ZR}_{n}}{\mathrm{MR}_{n}}-\mu_{\mathrm{R}}\left(\mathrm{MR}_{n}, \mathrm{FR}_{n}, \mathrm{Mr}_{n}, \mathrm{Fr}_{n}\right)\right| \geq \mathrm{MR}_{n}^{-\rho}\right\}
$$

are a.s. equal.

It remains to prove (16). If $\alpha<0.5$ and $\min \left\{\alpha \mathrm{m}_{\mathrm{R}}, \alpha \mathrm{m}_{\mathrm{r}}\right\}>1$, then Lemmata 6 and 7 ensure that

$$
A_{\infty, \infty}=A_{\infty, \infty} \cap\left\{\mathrm{F}_{n}<\mathrm{M}_{n} \text { eventually }\right\} \subseteq\left\{\mu_{\mathrm{R}}\left(\mathrm{MR}_{n}, \mathrm{FR}_{n}, \mathrm{Mr}_{n}, \mathrm{Fr}_{n}\right)=\frac{\mathrm{F}_{n}}{\mathrm{M}_{n}} \text { eventually }\right\} \quad \text { a.s. }
$$

and this gives (16) by an appeal to Lemma 3 (with $A=A_{\infty, \infty}$, which is allowed by Lemma 4 ). If $\alpha=0.5$ and $\min \left\{\alpha \mathrm{m}_{\mathrm{R}}, \alpha \mathrm{m}_{\mathrm{r}}\right\}>1$, then $\alpha /(1-\alpha)=1$ and (16) follows even directly from Lemmata 3 and 7 .

\section{Proof of Result 5.2}

Consider the assertion for the R-genotype. On $A_{\infty, \infty}$, we can write

$$
\frac{\mathrm{ZR}_{n+1}}{\mathrm{ZR}_{n}}=\frac{\mathrm{ZR}_{n+1}}{\mathrm{MR}_{n+1}} \frac{\mathrm{MR}_{n+1}}{\mathrm{ZR}_{n}}
$$

for all $n \geq 0$ and then infer, by using Lemmata 5 and 8 , that for each $0<\rho<1 / 2$

$$
\begin{aligned}
\frac{\mathrm{ZR}_{n+1}}{\mathrm{ZR}_{n}} & =\left(\frac{\alpha}{1-\alpha}+O\left(\mathrm{ZR}_{n}^{-\rho}\right)\right)\left((1-\alpha) \mathrm{m}_{\mathrm{R}}+O\left(\mathrm{ZR}_{n}^{-\rho}\right)\right) \\
& =\alpha \mathrm{m}_{\mathrm{R}}+O\left(\mathrm{ZR}_{n}^{-\rho}\right) \quad \text { a.s. on } A_{\infty, \infty}
\end{aligned}
$$


as $n \rightarrow \infty$. Since, furthermore,

$$
\frac{\mathrm{ZR}_{N}}{\left(\alpha \mathrm{m}_{\mathrm{R}}\right)^{N}}=\mathrm{ZR}_{0} \prod_{n=0}^{N-1} \frac{\mathrm{ZR}_{n+1}}{\alpha \mathrm{m}_{\mathrm{R}} \mathrm{ZR}_{n}}
$$

for each $N \geq 0$, a combination of (18), Lemma 4, and Theorem 7.28 in Stromberg (1981) allows us to conclude

$$
0<\prod_{n=0}^{\infty} \frac{\mathrm{ZR}_{n+1}}{\alpha \mathrm{m}_{\mathrm{R}} \mathrm{ZR}_{n}}<\infty \quad \text { a.s. on } A_{\infty, \infty}
$$

and hence the first assertion of Result 5.2. From this and Lemma 5, one can deduce the same result for $\mathrm{MR}_{n}$. All other assertions follow in a similar manner.

Since Result 5.3 is a direct consequence of Results 5.1 and 5.2, it requires no proof.

\section{Acknowledgements}

The authors would like to thank the anonymous referee for the constructive comments and interesting suggestions which have improved this paper.

The research of C. Gutiérrez and R. Martínez was supported by the Ministerio de Ciencia e Innovación and the FEDER through the Plan Nacional de Investigación Científica, Desarrollo e Innovación Tecnológica, grant MTM2009-13248.

\section{Disclosure Statement}

No competing financial interests exist.

\section{References}

Asmussen, S., Hering, H., 1983. Branching Processes. Birkhäuser.

Bagley, J., 1986. On the asmptotic properties of a supercritical bisexual branching process. J. Appl. Probab 23, 820-826.

González, M., Hull, D. M., Martínez, R., Mota, M., 2006. Bisexual branching processes in a genetic context: The extinction problem for Y-linked genes. Math. Biosci. 202, 227-247.

González, M., Martínez, R., Mota, M., 2008. Bisexual branching processes in a genetic context: Rates of growth for Y-linked genes. Math. Biosci. 215, 167-176.

González, M., Martínez, R., Mota, M., 2009. Bisexual branching processes to model extinction conditions for Y-linked genes. J. Theor. Biol. 258, 478-488.

Hush, D., Scovel, C., 2005. Concentration of the hypergeometric distribution. Statist. Probab. Lett. 75, $127-132$.

Quintana-Murci, L., Fellous, M., 2001. The human Y chromosome: the biological role of a "functional wasteland". J. Biomed. Biotechnol. 1, 18-24.

Stromberg, K. R., 1981. An introduction to real analysis. Wadworth and Books, Belmont. 